\title{
Financial performance of China's listed firms in presence of coronavirus: Evidence from corporate culture and corporate social responsibility
}

\author{
Fengjiao Zheng ${ }^{1} \cdot$ Zhiying Zhao $^{2} \cdot$ Yunpeng Sun ${ }^{3} \cdot$ Yousaf Ali Khan $^{4,5} \mathbb{C}$ \\ Accepted: 4 August 2021 \\ (C) The Author(s), under exclusive licence to Springer Science+Business Media, LLC, part of Springer Nature 2021
}

\begin{abstract}
Motivated from the shortage of the existing research studies on impacts of dangerously contagious diseases on firms' financial performance, this study sheds light on the impacts of Coronavirus (Covid-19) outbreak on financial performance upon on the quarterly data of 126 Chinese listed firms across 16 industries. Overall, the Covid-19 outbreak reduced Chinese listed firms' financial performance proxied by the revenue growth rate, ROA, ROE, and asset turnover. This outbreak's negative effects on Chinese firms' profitability were much smaller than that on their revenue growth rates. While this outbreak's negative effects on financial performance of Chinese listed firms were bigger for those that were seriously affected by this pandemic like airlines, travel, and entertainment (ATE), this pandemic's effects were positive for the medicine industry. In the meanwhile, Chinese listed firms that located in high-risk regions suffered a bigger financial loss during the outbreak, and especially there was a strong Hubei effect. The corporate culture and CSR moderated the inverse relationship between this outbreak and Chinese firms' financial performance. Findings of this study contribute to enrich the existing literature on impacts of the Covid-19 outbreak on firms' financial performance worldwide and suggest helpful practical and theoretical implications.
\end{abstract}

Keywords Financial performance $\cdot$ Chinese listed companies $\cdot$ Coronavirus $\cdot$ Corporate culture $\cdot$ Corporate social responsibility (CSR)

Yousaf Ali Khan

yousaf_hu@yahoo.com

Fengjiao Zheng

fengjiaozheng95@163.com

Zhiying Zhao

zhiying_zhao1995@hotmail.com

Yunpeng Sun

tjwade3@126.com

1 Centre for environment and sustainability, University of Surrey, Guildford, UK

2 Shanghai Momentvisa Business Consulting LtD., Shanghai, China

3 School of Economics, Tianjin University of Commerce, Tianjin, China

4 School of Statistics, Jiangxi University of Finance and Economics, Nanchang 330013, China

5 Department of Mathematics and Statistics, Hazara University Mansehra, Mansehra, Pakistan

\section{Introduction}

On December 31st, 2019, the first cases of the Covid19 (coronavirus) outbreak were reported in Wuhan city, China, making a critical milestone for the spread of this outbreak to other provinces of China as well as the world (Fernandes, 2020). To response to this crisis, China government decided to lockdown Wuhan city on January 23rd, 2020, and restricted both outbound and inbound travels (Taylor, 2020). This severe lockdown resulted in the slowdown of Chinese economy presented at the decline of industrial outputs and retailing revenue, and the increase of the unemployment rate. According to Bloomberg (2020), Chinese industrial outputs plummeted by $13.5 \%$ in January and February of the year of 2020 whereas the retailing sector's revenue declined by 20.5\%. The investment in fixed assets of Chinese firms plunged by $6.2 \%$. The unemployment rate climbed up to $6.2 \%$ in February 2020. As IMF estimated, the Chinese economy's slowdown would be approximately 0.4 percentage point (IMF, 2020). Thus, it would be expected that this outbreak might reduce Chinese listed firms' financial 
performance in the first quarter of 2020. However, at the firm level, impacts of the Covid-19 outbreak on firms' financial performance have not been explored in the world literature in general and in Chinese literature, in particular, whereas the evaluation of this outbreak's effects is critical to firms to determine their suitable business strategies when this dangerously contagious disease spreads.

Furthermore, the literature on impacts of contagious diseases (i.e., Maunder et al., 2003, Ebola, etc.) on firms' financial performance is scarce since the majority of the literature on this topic has focused on examining impacts of such diseases on stock markets' performance (Alber, 2020; Ali et al., 2020; Altig et al., 2020). Scholars revealed that dangerously contagious diseases negatively influenced investors' sentiment, which, in return, determined investors' investment decisions (Donadelli et al., 2017). As a result, stock prices presented the higher degree of volatility shaped by irrational investor behaviours when the dangerously contagious diseases spread (Zhang et al., 2020). Notably, the stock market may overreact to such diseases due to the herding behaviours and the spread of fear, so the stock market performance may not reflect well firms' financial performance. In the other words, the stock market inefficiency may exist. Hence, without the evaluation of impacts of such diseases on firms' financial performance, firms may not determine accurately their strategies to deal with the health crisis as well as to recover from this crisis.

This study, thus, is conducted with an aim to add an evidence on impacts of the Covid-19 outbreak on Chinese firms' financial performance, which have been underexplored in the relevant literature. It aims to clarify how this outbreak influenced Chinese listed firms' financial performance proxied by revenue growth rate, ROA, ROE, and asset turnover, using quarterly data due to the consideration to the unique feature of the spread of the Covid-19 pandemic in China and this country's strict measures. It also examines whether impacts of Covid-19 pandemic on financial performance of Chinese listed firms are heterogenous across industries and regions and whether corporate culture and corporate social responsibility (CSR) moderate effects of this dangerously contagious disease on financial performance of Chinese listed firms.

This study is different from the existing research studies on this topic (i.e., Aifuwa et al., 2020; Secinaro et al., 2020) since it utilizes the quarterly data of Chinese listed firms to examine impacts of the Covid-19 outbreak on their financial performance. The quarterly data reflects more accurately impacts of this outbreak on firms' financial performance since this outbreak emerged by the end of the fourth quarter of 2019 and deepened during the first quarter of 2020 in China. From April 7th, 2020, since China controlled well this outbreak, the lockdown was lifted in Wuhan (Goh, 2020), meaning that impacts of this outbreak on firms were lessened. Thereafter, China successfully controlled this outbreak and did not experienced the second wave of this health crisis like other countries because of the Government's strict measures. Hence, Chinese firms emerged from this crisis and performed better in other quarters.

This study is also unique since it controls for effects of firms' specific factors and their industry's characteristics on their financial performance to isolate impacts of the Covid-19 outbreak on their financial performance. It also takes into an account impacts of this pandemic on financial performance of Chinese listed firms in different industries and regions to figure out whether the Covid-19 pandemic poses heterogenous effects on financial performance of firms operated in different industries and located in different regions that are differently sensitive to the outbreak. Furthermore, this study examines the moderating role of corporate culture and CSR for effects of this pandemic on financial performance of Chinese listed firms since corporate culture and CSR performance may influence the relationship between firms and their stakeholders that enables firms to deal with the pandemic differently.

Since this study involves the panel data, the generalized least squares (GLS) with the cross-section weights and White cross-section method of coefficient covariance are applied to deal with the heteroscedasticity of cross-section, as well as the cross-section dependence of residuals (Hsiao, 2014). In general, this study has found that the Covid-19 outbreak harmed Chinese listed firms' financial performance in the first quarter of 2020 since it reduced revenue growth rate, ROA, ROE, and asset turnover of the studied firms in this quarter. Furthermore, the negative impacts of this outbreak on Chinese firms' revenue growth rate were highest with the decline of the revenue by $40 \%$ in this quarter. However, the negative effects of this outbreak on Chinese listed firms' ROA, ROE, and asset turnover were modest with just $0.3 \%, 0.7 \%$, and $5.2 \%$, respectively. Effects of this outbreak on Chinese listed firms' financial performance varied across industries, as well as firms with different working capital management strategies and capital structures. The heterogenous effects of this pandemic were also found in different regions with the strongest negative effects of this pandemic on financial performance of firms found in Hubei - the most severe affected region in this outbreak. Furthermore, corporate culture and CSR moderated the negative effects of this outbreak on Chinese firms' financial performance.

Following the introduction section, this study is constructed in four other sections. The literature review section clarifies the research background and the existing findings on impacts of dangerously contagious diseases on firms' performance. Subsequently, the methodology section provides details of the data collection process, the sampling method, and the research design. In the fourth section, details of the data analysis and findings are presented. Finally, achievements of the study and its limitations are summarized and recommendations to relevant stakeholders of the study are proposed. 


\section{Brief Literature Review}

\section{Firm Performance}

There are different theoretical perspectives of firm performance. The shareholder theory focuses on financial performance measures to examine how well firms maximize their profit to satisfy shareholder's needs (Friedman, 1970). Differently, the stakeholder theory considers the satisfaction of all stakeholders as an indicator of firm performance (Freeman et al., 2010). The balanced scorecard measures firm performance by four aspects - financial, customer, internal process, and learning and growth (Kaplan \& Norton, 1992). Disregarding views, financial performance is commonly agreed as an important performance of firms since it is an outcome of the triple bottom line performance, and it decides the survival and possible growth of firms in the long-term. According to the balanced scorecard perspective, firms, which have excellent learning and growth performance, can obtain the better internal process. In return, the better internal process leads to the better customer performance, which is an antecedent of financial performance. Furthermore, when financial performance is good as expected, it may become an antecedent of other non-financial performance (Kaplan \& Norton, 1996). For example, when firms are profitable, they can offer more incentives to their employees, leading to the better employee satisfaction and retention (Chi \& Gursoy, 2009).

Firms' financial performance refers to their effectiveness and efficiency in utilizing their assets and capital to generate revenue and profit (Wahlen et al., 2014). It is measured by several profitability measures (ROA, ROE, ROCE, etc.) and turnover ratios (asset turnover ratio, fixed asset turnover ratio, etc.). In which, profitability ratios measure the ability of firms to generate profit (Williams \& Dobelman, 2017) whereas turnover ratios measure the efficiency of firms in utilizing their assets and capital in generating revenue (White et al., 2003). Therefore, turnover ratios are also used as indicators of agency costs (Singh \& Davidson III, 2003). If agency conflicts are high, the management tends to underperform (Jensen, 1986), leading to the low asset turnover ratio as assets are not utilized efficiently (Garanina \& Kaikova, 2016). On the other hand, firm performance is also measured by market performance of firms' shares proxied by Tobin's Q (Fu et al., 2016). However, firms' market performance may be subjective to investor sentiment and/or other irrational behaviours (Zouaoui et al., 2011). Therefore, to examine firms' performance, accounting based measures are preferred since they reflect firms' intrinsic performance without influences of external factors. In this study, accounting measures are used instead of market-based indicators due to the consideration to the fear spread among stock markets caused by the negative effects of the Covid-19 pandemic.

\section{Internal Determinants of Firm Performance}

The literature indicates a number of determinants of firm performance. From the agency perspective, firm performance is influenced by agency conflicts as the management is selfinterest oriented (Jensen \& Meckling, 1976). Thus, they may engage in opportunistic activities by either claiming more resources than needed or underperforming to maximize their utility, leading to moral hazard facing shareholders. Their underperformance is supported by the asymmetric information, which refers to the information advantage possessed by the management over shareholders because of their involvement in firms' daily operation. Hence, to improve firm performance, agency conflicts must be minimized by the development of the effective corporate governance mechanisms. However, empirically, the strong corporate governance mechanisms are not enough to justify firms' performance (Arora \& Sharma, 2016; Bhagat \& Bolton, 2008; Buallay et al., 2017). Instead, other factors such as the effectiveness of business strategies and management capabilities determine how firms perform (Hansen \& Wernerfelt, 1989; Serra \& Ferreira, 2010).

Besides agency conflicts, working capital strategies adopted by firms also influence their financial performance (Sharma \& Kumar, 2011). Working capital is defined as the difference between current assets and current liabilities. The heavy investment in working capital, called the conservative working capital management, enables firms to response to customers' demand effectively (Afza \& Nazir, 2007). Consequently, customer satisfaction increases. Since customer satisfaction is an antecedent of customer loyalty and repurchase, firms' revenue increases. However, this strategy requires extensive storage and maintenance costs due to the high level of inventory held by firms (Raheman \& Nasr, 2007). Thus, firms' profitability may decline (Deloof, 2003). By contrast, the minimization of current assets, called the aggressive working capital management, minimizes costs incurred by firms since inventories are only replenished when demands emerge (just-in-time) (Afza \& Nazir, 2007). Consequently, firms' profitability increases. However, this strategy is risky as firms may not response effectively customers' demands and may have to borrow additional funds to accommodate their short-term liabilities (Raheman \& Nasr, 2007). Empirically, a large number of research studies support the trade-off between liquidity and profit as well as the negative impacts of the conservative working capital management on firm performance (Afza \& Nazir, 2007; Deloof, 2003; Raheman \& Nasr, 2007), etc.

On the other hand, the management of long-term debts is also critical since it influences firms' profitability (Myers, 2001). Firms have two sources of fund - debts and equity. The ratio between debt and equity determines firms' capital structure. According to Myers (1984), the financial leverage is a "double -edge sword" since it can provide both benefits and 
threats to firms. When firms increase their debts, they can gain tax shield benefit since interest expenses are tax deductible. Furthermore, with the issuance of debts, firms can avoid the dilution of their current shareholders' benefits. However, when debts are overused, the financial distress likelihood is likely. Furthermore, the inefficiency of investment projects funded by debts can harm firms' profit. Therefore, according to the static trade off theory, the determination of the optimal capital structure is critical to firms to ensure their optimal financial performance.

Under the production perspective, firm size is also a determinant of firm performance. With a large size, firms can gain economies of scale, which refers to the reduction of cost per unit (Stigler, 1958). Thus, firms can improve their profitability compared to others. However, according to Josefy et al. (2015), a big size requires extensive capital investment and the highly structured organization. Therefore, a large firm is inflexible to change, so it may not perform as good as small firm in the context of the uncertainty.

\section{Corporate Culture and Firm Performance}

Corporate culture is a collection of unique values and codes of conduct shared by a company's people. These values and codes of conduct shape the way people interact with each other and external stakeholders (Schein, 1985). Corporate culture is the soul and core of an enterprise, and it is a key factor that determines the firm performance and sustainable development.

Arogyaswamy and Byles (1987) stated that when the corporate culture had consistent values or beliefs with the corporate strategy, it had a positive effect on the firm performance. Denison (1990) argued that corporate culture affected a company's financial performance, its business strategy, its employees' work status, its innovation activities and financial information. Kotter John and Heskett (1992) analysed 72 companies from different industries in the United States and found that when companies paid more attention to key elements of corporate culture (i.e., beliefs and values associated with shareholders, consumers, and employees), firm performance was far better than those which did not focus on such key elements. However, Homburg \& Plfesser (2000) argued that corporate culture indirectly affected firm performance through the moderating role of market performance, and this relationship could be strengthened in a dynamic market. Similarly, Flamholtz and Kannan-Narasimhan (2005) also advocated that the effects of corporate culture on firm performance was not as direct as products, services, human resources, technology, and other factors. Instead, corporate culture had an indirect relationship with firms' financial performance. Molenaar et al. (2009) used the structural equation model to conduct a questionnaire survey on 196 individuals with good safety records and stated the safety culture of firm had a positive correlation with the construction performance. Huhtala et al. (2013) found that the ethical culture had a significant positive effect on managers' professional performance and work participation behaviour. Kaptein (2011) argued that the corporate culture could promote the employees' awareness and behaviour. Michalewicz and Fogel (2013) stated that if a company ignored the function of the corporate culture in governance, it would have caused a huge damage to the firm performance. Baysal et al. (2015) argued that companies with an innovative culture could promote their performance through the role of the managers with their high-level emotional intelligence. Vigolo et al. (2016) found that the service-oriented corporate culture could help to increase employee motivation and satisfaction, and thereby improved firm performance. However, some studies argued that corporate culture might exert the uncertainty effects on the firm performance. For example, corporate culture has a certain degree of stability, whereas the market demand is more flexible, so corporate culture cannot be adjusted in time with market changes, and it leads to the corporate performance reduction (Christensen, 1997). Pinho et al. (2014) argued that the different types of culture had different effects on the firm performance (i.e., the hierarchy culture negatively affected the firm performance). Zhao et al. (2018) found that corporate culture improvements negatively linked with firm value, and positively related to innovation outputs. However, there was an insignificant relationship between corporate culture with firm performance.

Despite different findings associated with impacts of corporate culture on firm's performance, majorities of the existing research studies argue that corporate culture is an important determinant of firm performance. A good corporate culture can promote organizational cohesion, build a joint force of stakeholders, and help promote performance improvement. In particular, corporate culture can better affect employees' job satisfaction and strengthen their organizational commitments.

\section{Corporate Social Responsibility and Firm Performance}

Emerged in the 1950s (Bowen, 1953), the concept of corporate social responsibility (CSR) is still in an ongoing debate among scholars. This concept has been explained by four distinct theoretical perspectives - the instrumental, the political, the integrated, and the ethical perspectives (Garriga \& Melé, 2004). The first theoretical perspective considers CSR as vehicles for firms to achieve their profit targets and to maximize shareholders' wealth (Friedman, 1970). The second advocates that CSR is needed for firms to realize their political power and to present their corporate citizenship (Davis, 1960; Davis, 1967; Davis, 1973). The third theoretical perspective argues that CSR is essential to firms since they need to discharge their accountability to different resource holders (Freeman et al., 2010). Thus, firms need to integrate demands 
of different stakeholders to their business strategies and performance. The fourth theoretical perspective considers that firms need to engage in CSR activities because of ethical reasons (Garriga \& Melé, 2004). Despite their differences in explaining the role of CSR, these theories share the common definition of CSR - social and environmental activities of firms that ensure their compliance with legal and ethical frameworks as well as the "self-enlightening" perspective (Davis, 1967). In terms of the linkage between CSR and firms' performance, this linkage has not been commonly agreed. While the neoclassical economics argues that CSR reduces firm performance because it adds additional costs to firms (Schröder, 2014), the integrative theory indicates that CSR brings rewards to firms because it enables firms to satisfy demands of different stakeholders (Bird et al., 2007), to prevent reputational risk facing firms (Minor \& Morgan, 2011), to increase employee's engagement and long-run stock return (Edmans, 2012). Differently, CSR effects on firm performance may be also neutral because its benefits are offset by its additional costs added to firms (Becchetti et al., 2008). The neutral effects of CSR on firms' market performance measured by market based indicators are also justified by impacts of external factors (i.e., investor sentiment, herding behaviours, etc.) on share prices as stated by the behavioural finance (Baker \& Wurgler, 2007).

\section{Dangerously Contagious Diseases and Firm Performance}

Dangerously contagious diseases refer to diseases, which are highly contagious among people and require extensive healthcare resources to prevent and cure. Example of such diseases are Spain Flu, SARS, MERS, Ebola, Covid19, etc. (Rajakaruna et al., 2017). Thus, when these diseases emerge, the lockdown may be implemented to prevent the transmission of such diseases from people to people, leading to the disruptions of business' supply chains. Consequently, job loss, income decrease, and consumer expenditure decline happen, leading to macroeconomic headwinds facing firms (Fernandes, 2020).

The literature on impacts of such diseases on firms' financial performance is scarce since most of the existing research studies focus on examining impacts of such diseases on the stock market (firms' market performance) (Alber, 2020; Ali et al., 2020; Donadelli et al., 2017). However, the heterogeneity in impacts of such diseases on stock market has been found. While such diseases create fear spreading among investors, leading to their negative sentiment, they also improve investor sentiment against the pharmaceutical sector. Investors of this sector expects that the development of vaccine can maximize returns of pharmaceutical stocks in the future (Donadelli et al., 2017). Related to the Coronavirus outbreak, scholars found that this outbreak negatively influenced most stock markets in the outbreak- severely- infected countries (Alber, 2020; Ali et al., 2020; Altig et al., 2020).

Regarding impacts of dangerously contagious diseases on firms' financial performance, four typical research studies are noticeable in the literature.

Jung et al. (2016) examined impacts of MERS outbreak on customer expenditures in Korea. They found that total expenditures reduced significantly due to this outbreak, but the heterogeneity existed across categories. When customer expenditure declines, firm performance is negatively affected since the reduction of customer demand leads to the reduction of firms' revenue as well as their profit.

Secinaro et al. (2020) examined how 2003 SARS influenced the performance of medium companies in the travel and leisure sector in Europe. This study employed the content analysis of annual reports to compare the financial performance and position of three companies in 2002 (before the 2003 SARS) and in 2003 (SARS). They found that the 2003 SARS did not severely affect these companies' financial performance and position. However, this study utilized the absolute value of financial data of three studied firms instead of financial ratios, so the analysis was weak. Furthermore, with the small sample size involved, outcomes of this study could not be well generalized, and it lacked the empirical evidence support.

Aifuwa et al. (2020) investigated impacts of the Coronavirus on financial and non-financial performance of Nigerian firms. They adopted the survey, targeting to owners of private business and financial analysts in Lagos State, where experienced the highest number of infected cases in Nigeria. By the adoption of the OLS, this study revealed that Coronavirus harmed both financial and non-financial performance of these firms. However, since this study utilized primary data, which associated with the perception of business owners and financial analysts, outcomes were subjective to such perceptions rather than the real impacts of this outbreak on firm's financial performance presented at the variance of their financial data.

Hassan et al. (2020) revealed that since the emergence of the Covid-19 outbreak, firms were mostly concerned with the collapse of demand, the increase of uncertainty, and the disruption of their supply chain, the reduction of capacity, closures, and employee welfare. Surprisingly, firms did not express much concern on their financial performance. Furthermore, many firms could also foresee business opportunities in new and/or disrupted markets caused by the spread of this disease. Moreover, firms, which had the experience with SARS or H1N1, presented their positive expectations about their ability to response to this outbreak.

In this study, the effects of Covid-19 pandemic that is one of dangerously contagious disease on financial performance of Chinese firms are investigated. The Covid- 
19 outbreak, after its emergence in December 2019 in Wuhan, spread China nationwide rapidly (Bloomberg, 2020). Thus, a severe lockdown was implemented by the Government in Hubei province as an attempt to prevent the contagiousness of this outbreak. Furthermore, the social distancing and selfquarantines were also implemented (Nicola et al., 2020). The severe lockdown in Hubei province and the tight quarantine process resulted in the disruption of Chinese firms' supply chains. Businesses had to close and/or limit their operations towards the assurance of their people health. Thus, the number of people losing their jobs increased. Customers also cut their spending for unnecessary goods and services due to the fear of this outbreak and the uncertainty (Fernandes, 2020). According to Aifuwa et al. (2020), the Covid-19 pandemic harmed both financial and non-financial performance of firms whereas Hassan et al. (2020) argued that this outbreak resulted in the collapse of demands, the disruptions of supply chain, the decrease of employee wellbeing, and the increase of uncertainty. Hence, this study hypothesizes that the Coronavirus outbreak reduced the financial performance of Chinese listed firms in the first quarter of 2020.

H1 The Coronavirus outbreak reduced the financial performance of Chinese listed firms.

According to Donadelli et al. (2017), a dangerously contagious disease may create the inverse effects on firms' performance. Furthermore, Nicola et al. (2020) stated that in the context of the contagiousness of the Coronavirus outbreak, demands for commodities and manufactured products declined whereas demands for medical supplies and food products soared. Additionally, while the service sector might be highly suffered from this outbreak as mentioned by Fernandes (2020), other sectors might not. However, firms' financial performance might vary due to response of firms to this outbreak. According to Ritter and Pedersen (2020), impacts of the coronavirus outbreak on business-to-business firms were divergent due to their different business models that would help them to response differently to this outbreak. Thus, impacts of this outbreak on financial performance of Chinese listed firms in different industries might not be convergent.

H2 There is a heterogeneity in impacts of the Coronavirus outbreak on the financial performance of Chinese listed firms in different industries.

After the emergence of this outbreak in Wuhan city, Hubei province, this outbreak spread to 31 other provinces in China since January 2020. During the first quarter of the year of 2020 , there was a large number of confirmed and fatal cases of this outbreak in the coastal, central, and western regions in China. As a response to this public health emergency, China's President $\mathrm{Xi}$ Jinping claimed the disease prevention and control as the country's top priority rather than economy reopening (Nicola et al., 2020). Under this scenario, companies in different regions shut down their production lines, and thus their supply chains were negatively affected (Schleicher, 2020). For the demand side, the household's consumption demands were obviously suppressed by the Coronavirus outbreak (Fernandes, 2020). Thus, impacts of this outbreak on the financial performance of Chinese listed firms in severe epidemic regions might be stronger than that in other regions.

H3 The impacts of Coronavirus outbreak on financial performance of Chinese listed firms in severe areas are stronger than that in other regions.

The Coronavirus outbreak created a big and adverse shock to the financial performance of listed companies in China (Bloomberg, 2020). Under this sudden crisis, listed companies in China relied on their corporate culture to influence behaviours and attitudes of their employees and enterprise managerial positions. The existing corporate culture is a valuable asset of an enterprise, and it is hard to imitate. It is a psychological contract among people that enables them to have the mutual recognition and understanding about the relationship and interaction between employees, managerial positions, and the entire organization in general (Baysal et al., 2015). The corporate culture can foster people to innovate and figure out the best way to protect themselves from this outbreak under the supports of their firms as well as to maximize firms' performance. Thus, the corporate culture is hypothesized to have moderating effects on the relationship between the coronavirus outbreak and Chinese listed firms' financial performance.

H4 The corporate culture has moderated impacts of the Coronavirus outbreak on the financial performance of Chinese listed companies.

The stakeholder theory (Freeman et al., 2010) as well as the integrated theories of CSR (Garriga \& Melé, 2004) suggest that the investment in CSR enables firms to satisfy better stakeholders' demands, leading to the better employee engagement, the more sustainable supply chain, and the higher reputational position. Consequently, firms' performance can be improved. In the context of the spread of Coronavirus outbreak, the CSR disclosure may provide positive signals to the market about good relationships between firms and their stakeholders, which, in returns, enable firms to improve their financial performance. Hence, the CSR is hypothesized to have moderating effects on impacts of the Coronavirus outbreak on the financial performance of Chinese listed companies.

H5 Corporate social responsibility has moderated effects on the negative impact of Coronavirus on financial performance of Chinese listed companies.

China is differentiated from other countries because of its political economic model (Myers, 1995). It aims to develop the socialist market economy, in which, the state own firms (SOEs) play the critical role as this economy's backbone. 
SOEs have large sizes, which enable them to obtain economies of scale. Furthermore, they receive significant financial and non-financial supports from the Government compared to non-state own firms (Ralston et al., 2006). Therefore, when this outbreak spreads, SOEs may easier access to the government supports to deal with this crisis than non-state own firms. The negative effects of this outbreak on SOE's financial performance, hence, may be lessened.

H6 Chinese SOEs experience fewer negative effects of the coronavirus outbreak on their financial performance than non-state own firms.

\section{Methodology and Data}

\section{Data}

This study adopts the stratified sampling method (Zikmund et al., 2013) to select Chinese listed firms as samples. The stratified sampling method is a sample selection method based on the theory of probability (Zikmund et al., 2013). It divides the total population to different segments and then randomly selects samples from each segment. This method, thus, enables random samples can be selected across different segments, so the representation of samples for the total population can be assured (Bryman \& Bell, 2015).

In this study, total population (Chinese listed firms) is divided in 16 different industries. Subsequently, the random selection of samples in each industry is made to ensure that samples well represent the population. The number of firms in each industry is determined based on the magnitude of each industry with more samples selected from the larger industries. The final sample size is 126 listed firms from both Shanghai and Shenzhen stock markets. These firms are classified into 16 industries, as shown in Table 1. For each sample, the quarterly financial data is gathered from Wind Database from the second quarter of the year of 2019 to the second quarter of the year of 2020. This period is selected because it involves quarters with and without impacts of the Coronavirus outbreak. Thus, the author can examine impacts of this outbreak on Chinese firms' financial performance. Among such quarters, Chinese firms were not affected by the Coronavirus outbreak in the Q2, Q3, and Q4 of the year of 2019, whereas they were influenced by this outbreak in Q1 2020 and Q2 2020. The selection of different quarters of the year of 2019 without impacts of the Coronavirus outbreak is justified by the possibility of the seasonal effects on Chinese firms' financial performance (Mor et al., 2019). Therefore, the selection of multiple quarterly data of the year of 2019 without impacts of this outbreak can address the problem of seasonal impacts. Furthermore, this selection also enables the study to eliminate impacts of change in corporate governance of Chinese listed firms since board of directors and corporate governance mechanisms were already determined throughout these quarters.

\section{Research Models}

This study develops several research models that capture impacts of the Covid-19 outbreak on Chinese listed firms' financial performance.

$$
\begin{aligned}
& \text { REG } / \text { ROA } / \text { ROE } / \text { ATO }=\alpha+\beta 1 \text { COVID } 19 \\
& +\beta_{2} \text { FCC }+\beta_{3} \text { FCSR }+\beta_{4} \text { Liquidity } \\
& +\beta_{5} \text { Efficiency }+\beta_{6} \text { Leverage }+\beta_{7} \text { SO }+\beta_{8} \text { Size } \\
& +\beta_{9} \text { Industry }+\varepsilon
\end{aligned}
$$

In which, Chinese firms' financial performance is proxied by the revenue growth rate (REG), return on assets (ROA), return on equity (ROE), and asset turnover (ATO). REG is measured by the logarithmic value of a Chinese firm's revenue generated in the quarter $t$ scaled by its revenue generated in the quarter t-1. ROA is measured by a Chinese firm's net income generated at the end of each quarter scaled by its corresponding total assets. The measure of ROE is the ratio between a Chinese firm's net income at the end of each quarter and its corresponding total equity. Asset turnover (ATO) is measured by a Chinese firm's revenue generated at the end of each quarter scaled by its corresponding total assets. While the revenue growth rate is a simple measure of the ability of Chinese listed firms in generating revenue, ATO measures firms' abilities in generating revenue in the comparison with their total assets (Williams \& Dobelman, 2017). ATO, thus, is also a proxy of agency costs (Garanina \& Kaikova, 2016). Differently, ROA and ROE are two measures of profitability of Chinese listed firms. The Coronavirus outbreak is measured by a binary variable with 1 proxied for the quarter with Coronavirus outbreak and 0 for otherwise. CSR, referring to the corporate social responsibility factor, and $\mathrm{CC}$, referring to the corporate culture, are constructed based on the Principal Component Analysis (PCA) method. This method extracts key factors from a large number of the raw variables without biasness while ensuring the data pattern can be maintained. Key variables of CSR and CC are retained when their Eigenvalues are higher than 1. Subsequently, the CSR and $\mathrm{CC}$ indexes are constructed based on the identified weight of each variable distributed to each sample scaled by the gap between the max and min weight of all samples. In the Appendix Table 12, the name of each raw variable used to measure CSR and CC and their measurement are provided.

Since Chinese firms' financial performance may be also influenced by their specific factors rather than the Coronavirus outbreak, firms' specific factors and their 
Table 1 General profile of samples by industries

\begin{tabular}{llll}
\hline No & Industry & Number of companies & Percent \\
\hline 1 & Airlines & 10 & $8.06 \%$ \\
2 & Tourism & 12 & $9.68 \%$ \\
3 & Retailers & 10 & $8.06 \%$ \\
4 & Healthcare & 6 & $4.84 \%$ \\
5 & Basic materials & 16 & $12.90 \%$ \\
6 & Automobile & 1 & $0.81 \%$ \\
7 & Energy & 5 & $4.03 \%$ \\
8 & Industrials & 10 & $8.06 \%$ \\
9 & Food processing \& agriculture products & 9 & $7.26 \%$ \\
10 & Entertainment & 1 & $0.81 \%$ \\
11 & Construction & 8 & $6.45 \%$ \\
12 & Beverage & 7 & $5.65 \%$ \\
13 & Textile & 10 & $8.06 \%$ \\
14 & Paper manufacturing & 5 & $4.03 \%$ \\
15 & Technology & 9 & $7.26 \%$ \\
16 & Real Estate & 7 & $4.03 \%$ \\
\hline
\end{tabular}

industries are controlled to isolate impacts of the Coronavirus outbreak on their financial performance.

According to Afza and Nazir (2007), there are different working capital management strategies that may influence firms' profitability. The aggressive strategy is characterized by the low investment in current assets, including the low inventory level. This strategy aims to eliminate inventory costs and to reduce payment delay from credit customers. Therefore, this strategy can enable firms to generate more profit (Afza \& Nazir, 2007). By contrast, the conservative strategy is featured by the high investment in current assets, including the high inventory level. This strategy aims to quickly response to the customer demand's fluctuations. However, with the more inventories held, firms have to incur the higher inventory holding costs, leading to the reduction of their profit (Raheman \& Nasr, 2007). Therefore, there is a trade-off between liquidity and profit, which means that the more current assets held by firms, the low degree of profitability generated by firms. Hence, liquidity, measured by current assets scaled by current liabilities, and efficiency, measured by cash conversion period (CCC), are used as the control variables for the relationships between the financial performance of Chinese listed firms and the coronavirus outbreak's impacts. CCC is the gap between the sum of inventory and receivable day ratios after the subtraction of payable day ratio (Wahlen et al., 2014).

On the other hand, the capital structure proxied by total debts scaled by total liabilities, is also a "double-edge sword" used by firms (Myers, 1984). The high degree of financial leverage may increase firms' profitability when debts are used properly because firms can obtain tax shield effects and higher rate of return caused by highly leveraged projects. However, if debts are overused for the overinvestment activities, firms may experience the decline in their profit ratios due to the high debt burden while profit generated from investment projects may not as good as expected. Furthermore, the high level of financial leverage increases the financial distress likelihood facing firms. Hence, capital structure is also controlled to examine more accurately impacts of the Coronavirus outbreak on the financial performance of Chinese listed firms.

As mentioned by Ralston et al. (2006), SOEs play the backbone role in Chinese economy, so they receive significant supports from the Government, especially in the Coronavirus outbreak context. Therefore, SOEs may generate higher revenue than non-state own firms. The size of SOE is also large, so they may obtain economies of scale (Stigler, 1958), leading to the reduction of their cost per unit and the increase of their profitability. Therefore, impacts of the Coronavirus outbreak on their financial performance may be lessened.

Finally, firm size and industry are also controlled for the relationship between the financial performance of Chinese listed firms and the coronavirus outbreak's effects. Firm size may provide economies of scale to firms (Stigler, 1958), leading to the reduction of their cost per unit. Industry specific factors may influence the magnitude of impacts of the coronavirus outbreak on Chinese listed firms' financial performance because each industry has its own characteristics that make their response to the outbreak different from others. Firm size is measured by the logarithmic value of their total assets whereas industry is measured by a dummy variable.

On the other hand, the effect of the Covid-19 outbreak may vary across industries, state ownership, and regions classified by geographic locations and the seriousness of the Covid-19, so different research models would be developed to test for the heterogeneity of this outbreak's effect. 
The effect of COVID19 would be larger for Chinese listed firms in the medicine/pharmaceutical industry.

$$
\begin{aligned}
& \text { REG/ROA/ROE } / \text { ATO }=\alpha+\beta 1 \text { COVID } 19 \\
& +\delta 1 \text { COVID19* medicine }+\delta 2 \text { COVID19* ATE } \\
& +\beta_{2} \text { CC }+\beta_{3} \text { CSR }+\beta_{4} \text { Liquidity }+\beta_{5} \text { Efficiency } \\
& +\beta_{6} \text { Leverage }+\beta_{7} \text { SO }+\beta_{8} \text { size }+\beta_{9} \text { industry }+\varepsilon
\end{aligned}
$$

While $\beta_{1}$ measures the average effect of COVID19 outbreak, $\left(\beta_{1}+\delta 1\right)$ measures the specific effect of COVID19 on Chinese listed firms in the medicine-related industry. $\left(\beta_{1}+\right.$ $\delta 2$ ) measures the specific effect of the COVID19 outbreak on Chinese listed firms in related Airlines, Tourism and Entertainment industry, named as ATE.

The effect of this outbreak may vary across regions, including the dangerously seriously risky region and the dangerously high risky region. Therefore, a number of research models would be developed to capture the heterogeneity of such effect across regions.

For the dangerously seriously risky regions, research models are developed as followings:

$$
\begin{aligned}
& \text { REG/ROA/ROE } / \text { ATO }=\alpha+\beta 1 \text { COVID } 19 \\
& +\delta \text { COVID19*DSR }+\beta_{2} \text { DSR }+\beta_{3} \text { CC }+\beta_{4} \text { CSR } \\
& +\beta_{5} \text { Liquidity }+\beta_{6} \text { Efficiency }+\beta_{7} \text { Leverage } \\
& +\beta_{8} \text { SO }+\beta_{9} \text { size }+\beta_{10} \text { industry }+\varepsilon
\end{aligned}
$$

Where DSR represents the dangerously serious regions affected from the Coronavirus outbreak, which measured by the number of the confirmed COVID-19 cases/ provincial (city) population. If this ratio equals 1 , the number of the confirmed cases/ provincial (city) population is more than the median of the country. Thus, these regions have been recognized as seriously affected by the COVID-19 outbreak.

For the dangerously highly risky regions, research models are developed as:

$$
\begin{aligned}
& \text { REG } / \text { ROA } / \text { ROE } / \text { ATO }=\alpha+\beta 1 \text { COVID } 19 \\
& +\delta \text { COVID19 } * \text { DHR }+\beta_{\mathbf{2}} \text { DHR }+\beta_{3} \text { CC }+\beta_{4} \text { CSR } \\
& +\beta_{5} \text { Liquidity }+\beta_{6} \text { Efficiency }+\beta_{7} \text { Leverage } \\
& +\beta_{\mathbf{8}} \text { SO }+\beta_{\mathbf{9}} \text { size }+\beta_{10} \text { industry }+\varepsilon
\end{aligned}
$$

Where DHR represents the high-risk regionals in Coronavirus outbreak, which measured by the number of COVID-19 death cases/ provincial (city) population, which equals 1 indicates the number of confirmed cases/ provincial (city) population are more than the median, these regions are high-risk of the COVID-19.

To test for the heterogeneity of the effect of this outbreak across geographical regions in China, several regression models would be developed.

$$
\begin{aligned}
& \text { REG } / \text { ROA } / \text { ROE } / \text { ATO }=\alpha+\beta 1 \text { COVID } 19 \\
& +\delta \text { COVID19 } * \text { EAST }+\beta_{2} \text { CSR }+\beta_{3} \text { Liquidity } \\
& +\beta_{4} \text { Efficiency }+\beta_{5} \text { Leverage }+\beta_{6} \text { SO }+\beta_{7} \text { size } \\
& +\beta_{8} \text { industry }+\varepsilon
\end{aligned}
$$

$$
\begin{aligned}
& \text { REG } / \text { ROA/ROE } / \text { ATO }=\alpha+\beta 1 \text { COVID } 19 \\
& +\delta \text { COVID19*CENTRAL }+\beta_{2} \text { CSR } \\
& +\beta_{3} \text { Liquidity }+\beta_{4} \text { Efficiency }+\beta_{5} \text { Leverage } \\
& +\beta_{6} \text { SO }+\beta_{7} \text { size }+\beta_{\mathbf{8}} \text { industry }+\varepsilon
\end{aligned}
$$

REG $/$ ROA $/$ ROE $/$ ATO $=\alpha+\beta 1$ COVID $19+\delta$ COVID19

$$
\begin{aligned}
& * \text { West }+\beta_{2} \text { CSR }+\beta_{3} \text { Liquidity }+\beta_{4} \text { Efficiency } \\
& +\beta_{5} \text { Leverage }+\beta_{6} \text { SO }+\beta_{7} \text { size }+\beta_{8} \text { industry }+\varepsilon
\end{aligned}
$$

To explore this outbreak's effect across the corporate culture and CSR of Chinese state-own listed companies, four research models would be developed as following:

$$
\begin{aligned}
& \text { REG } / \text { ROA } / \text { ROE } / \text { ATO }=\alpha+\beta 1 \text { COVID } 19 \\
& +\delta \text { COVID19*DSO }+\beta_{2} \text { CC } \\
& +\beta_{3} \text { COVID19*DSO } * \text { CC }+\beta_{4} \text { CSR } \\
& +\beta_{5} \text { COVID19*DSO } * \text { CSR }+\beta_{6} \text { Liquidity } \\
& +\beta_{7} \text { CCC }+\beta_{8} \text { Leverage }+\beta_{9} \text { size }+\beta_{10} \text { industry } \\
& +\varepsilon
\end{aligned}
$$

\section{Data Analysis}

In this study, six hypotheses were developed, and they would be tested through the conduction of the regressions for panel data (McManus, 2015). These regressions consider the problems of the panel data such as heteroscedasticity, autocorrelation, and effects of either cross-section or period. To determine which type of cross-sectional regressions is the best suitable for panel data gathered, firstly, the ordinary least squares 
(OLS) is performed for the developed models with the implementation of both fixed and random-effects and the conduction of Hausman test to figure out the suitable effects (Asteriou \& Hall, 2015). Then, the cross-section dependence test is performed to figure out whether the cross-section heteroscedasticity exists. The residual tests are also performed to figure out whether autocorrelation of residuals appears. Because of the existence of the contemporaneous heteroscedasticity and autocorrelation, the generalized least squares (GLS) should be performed with the cross-sectional weights and the White cross-section covariance method applied. The White cross-section variance method is robust for both the contemporaneous heteroscedasticity and the crosssection dependence of residuals (McManus, 2015). Thus, it is a powerful covariance method that can be adopted for the panel data used in this study (Kutner et al., 2004).

\section{Empirical Results and Discussion}

\section{Descriptive Statistics}

Table 2 provides key statistics of variables of 126 firms involved in this study. Among past quarters, the quarter ended on March 31st, 2020, witnessed the spread of the Covid-19 outbreak whereas three remaining quarters did not. Thus, since this outbreak is measured by a binary variable with 1 coded for the period with this outbreak and 0 for otherwise, its mean is 0.25 , implying that this outbreak just existed in one over 4 studied quarters. Regarding the financial performance and position of Chinese firms, in four quarters (Q2, 2019- Q1, 2020), the revenue growth rate of Chinese listed firms was negative on the average $(-0.151)$. However, their ROA, ROE, and ATO were positive with 0.005, 0.011. and 0.017, respectively. This means that Chinese listed firms maintained the positive profitability ratios and asset turnover ratio in past four quarters despite their average negative revenue growth rates. The positive average ROA, ROE, and asset turnover reflects the possibility of positive gains from the Coronavirus outbreak in some industries in China as mentioned by Nicola et al. (2020). These gains offset losses of others, leading to the slightly positive average profitability and asset turnover ratios of Chinese firms in the studied quarters. The corporate culture index and CSR index of Chinese listed firms were more than 0.67 and 0.58 , respectively with the moderate standard deviation. This meant that Chinese listed firms had relatively good corporate culture and CSR with the moderate degree of differences in the corporate culture and CSR among firms. In terms of the data distribution pattern, all of variables are not normally distributed due to the significance of Jarque-Bera statistics at $1 \%$ level. The deviation of data from the mean value of all variables is relatively high due to the high standard deviation

\section{Correlation Analysis}

Table 3 provides the bivariate associations between variables. Except the strong positive correlation between ROA and ROE (0.95); the moderate correlation between revenue growth rate and CCC (-0.544); the moderate correlation between size and capital structure (0.596); and the moderate correlation between $\mathrm{CC}$ and CSR (0.532) were figured out. Other variables had either modest or insignificant correlations. However, since ROA and ROE would not be involved in the same regressions, the high degree of association between them does not matter to the regression quality. The moderate correlations found in this study would not highly likely create the multicollinearity of regressions (Kutner et al., 2004).

\section{Regression Analysis}

\section{Effects of Coronavirus Outbreak on Financial Performance of Chinese Listed Companies}

Table 4 provides outcomes of the Generalized Least Squares (GLS), using the White cross-section covariance method and Cross-section weights. This regression method was adopted since the heteroscedasticity of the cross-section has been detected from the Cross-section dependence test (Wooldridge, 2015). The GLS with cross-section weights, using the White cross-section covariance method, performs best to justify the variation of revenue growth rates of Chinese listed firms caused by the Coronavirus outbreak whereas the ability of this outbreak in explaining the variation of Chinese firms' ROA is lowest. F-values of all regressions have the probability lower than 0.01 , so these models outperform the intercept models (Wooldridge, 2015). In all models, coefficients of the coronavirus outbreak variable are significant at 0.01 significance level, so this outbreak can predict the variation of Chinese firms' financial performance proxied by four mentioned measures (McManus, 2015). Coefficients of the coronavirus outbreak variable are -0.3994 in the model (1), -0.003 in the model (2), -0.008 in the model (3), and -0.052 in the model (4). Thus, in the first quarter of the year of 2020 with the severe effects of the coronavirus outbreak, Chinese firms' revenues growth rates decreased by $39.94 \%$ whereas their ROA and ROE dropped slightly by $0.3 \%$ and $0.8 \%$, respectively when other variables are controlled. This outbreak reduced Chinese firms' asset turnover ratios by $5.2 \%$, assuming no change in other variables. In the other words, the coronavirus outbreak negatively influenced Chinese listed firms' financial performance in the quarter ended March 31st, 2020. However, the magnitude of this outbreak's negative impacts on Chinese firms' revenue growth rates was strongest whereas such impacts on profitability and asset turnovers were modest.

Besides the negative impacts of the coronavirus outbreak on Chinese listed firms' financial performance, other 


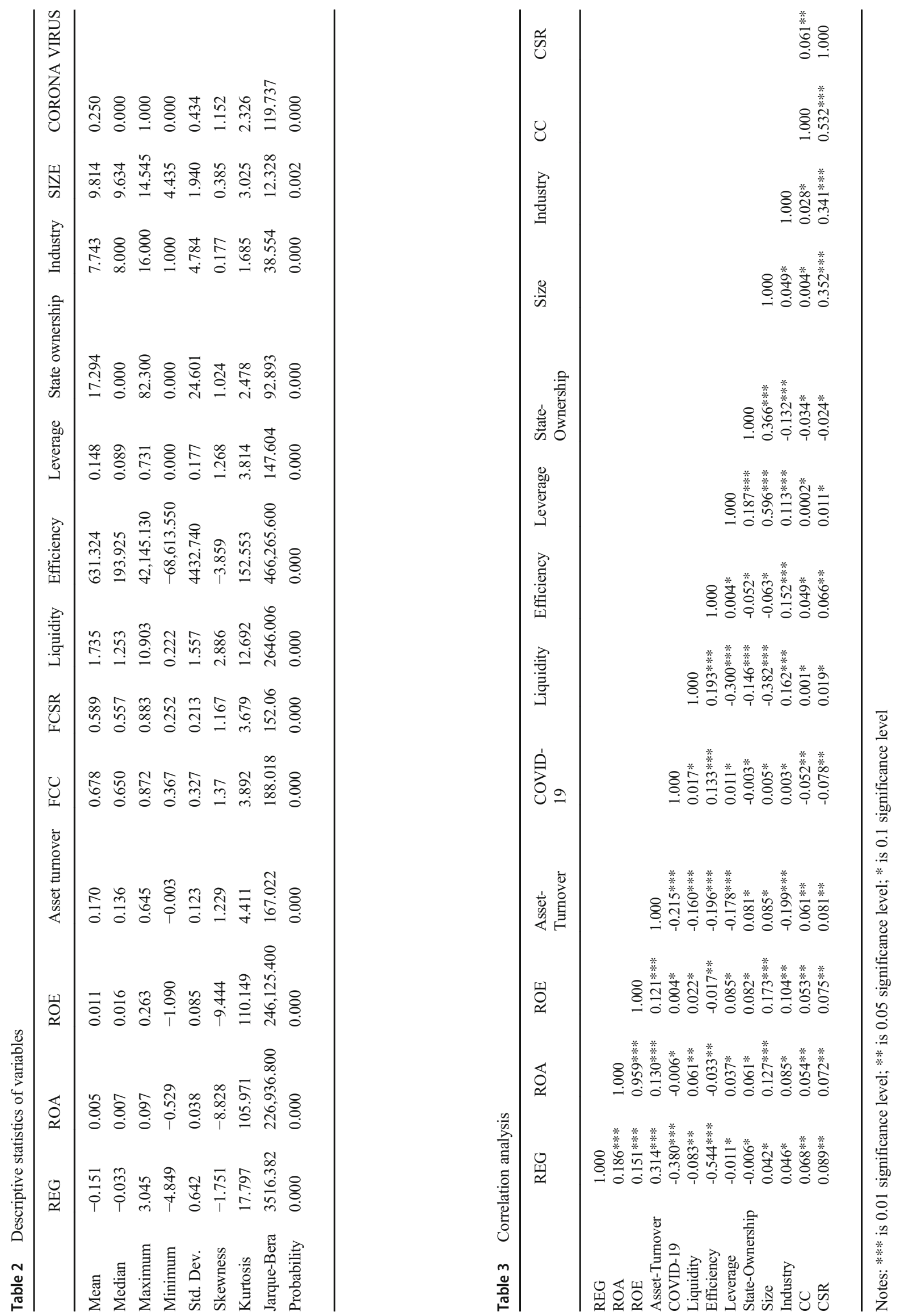


determinants of their financial performance were also figured out in four regression models. In the model (1), Chinese firms' liquidity and capital structure negatively affect their revenue growth rates although such effects were modest $(-0.01$ and 0.075 , respectively). This means that in the coronavirus outbreak context, firms with one-unit higher current ratio and one-unit higher financial leverage experienced $1 \%$ and $7.5 \%$ lower revenue growth rates when remaining variables were controlled. (Asteriou \& Hall, 2015). Differently, the industry specific factors, corporate culture, and CSR positively influenced Chinese listed firms' revenue growth rates with the significant coefficient at 0.01 level. Thus, in the context of this outbreak, Chinese listed firms' revenue growth rates varied across industries. Travel and Leisure industry experienced the highest revenue decline, followed by Retailer, Healthcare, and Basic materials. By contrast, other industries such as Technology, Paper production experienced the lowest revenue decline in this outbreak. Furthermore, corporate culture and CSR also improved the revenue growth rates of Chinese listed firms but their positive effects on Chinese listed firms' revenue growth rates were modest. In the model (2), liquidity, firm size, industry, corporate culture, and CSR positively influenced Chinese listed firms' ROA. This means that firms with the higher current ratios obtained higher ROA. With the high investment level in current assets, which include inventories, receivables, and cash and cash equivalent, Chinese firms could serve customer demand better by reducing the lead-time (Raheman \& Nasr, 2007). When the supply chain disruptions caused by the severe lockdown became seriously (Hassan et al., 2020), the substantial inventory level could benefit Chinese listed firms. Furthermore, with the high degree of cash and cash equivalent, firms could also finance their short-term liabilities simply, leading to the reduction of interest expenses caused by additional borrowing as well as the loss of sudden inventory conversion. Firms with the larger size also experienced the higher ROA because of the economies of scale obtained by large firms (Stigler, 1958). Furthermore, Chinese firms' ROA varied across industries, but this variation was modest because the coefficient of the industry variable was small (0.0004). Both corporate culture and CSR could improve ROA because their coefficients were statistically positive. However, positive impacts of corporate culture and CSR on Chinese firms' ROA were modest. By contrast, capital structure negatively influenced Chinese firms' ROA. The high financial leverage degree of Chinese listed firms led to their high interest burdens (Myers, 1984). Consequently, firms with the higher debt level experienced the lower ROA. Similarly, in the model (3), liquidity, firm size, industry, corporate culture, and CSR also positively linked with ROE. Chinese firms with the conservative working capital management, larger size, stronger corporate culture, and stronger CSR disclosure obtained the higher ROE. However, ROE varied across industries of firms when other factors were controlled. By contrast, Chinese firms with the higher debt level experienced the lower ROE due to the higher debt burdens (Myers, 1984). Notably, the difference in impacts of the Coronavirus outbreak on the financial performance of Chinese listed firms caused by different firms' unique characteristics was marginal. In the model (4), Chinese listed firms' asset turnover was negatively affected by liquidity, cash conversion cycle, capital structure, and industry whereas it was positively influenced by the state ownership, corporate culture, CSR, and firm size.

\section{Effects of Coronavirus Outbreak on Financial Performance of Chinese Listed Companies in Different Industries and Regions}

Table 5 provides outcomes of tests for the industry heterogeneity in impacts of the Covid-19 outbreak on Chinese firms' financial performance. Coefficient of Medical industry was significant and positive in all models, so in the context of this outbreak, Chinese medical firms obtained the higher financial performance, which is similar with the results of Sun et al. (2021). By contrast, coefficient of the ATE variable was significant and negative, so Chinese travel, entertainment, and airline firms obtained the lower financial performance than others in this outbreak. The interaction terms between the Covid-19 outbreak and Medicine were significant and positive in all models, so the negative effects of this outbreak on firms' financial performance in the medicine industry was reduced (Sun et al., 2021). Differently, the interaction terms between this outbreak and ATE were significant and negative in all models, so the negative impacts of this outbreak on financial performance of ATE industries increased. The test outcome confirmed the Hypothesis 2.

Table 6 provides outcomes of the tests for the regional heterogeneity in impacts of the Covid-19 outbreak on Chinese listed firms' financial performance. The coefficients of DSR in all models were significant and negative, meaning that the Covid-19 outbreak negatively reduced financial performance of firms located in the dangerously serious risky regions although such negative effects were modest. The interaction terms between the Covid-19 outbreak and DSR was significant and negative, so the negative impacts of this outbreak on the financial performance of firms in the dangerously serious risky region were deepened or DSR positively moderated the negative relationship between this outbreak and firms' financial performance in this region.

Table 7 provides the outcomes of tests for the heterogeneous impacts of the Covid-19 outbreak on Chinese firms' financial performance across dangerously highly risky regions (DHR). The interaction terms between the Covid-19 outbreak and DHR were significant and negative in all models, so in dangerously highly risky regions, Chinese firms experienced the more severely negative impacts of the Coronavirus outbreak than others. Compared with the DSR, the coefficient of interaction terms between the Covid-19 outbreak and DHR were stronger. 
Table 4 Generalized linear regression (cross-section weights $\&$ white cross-section variance method)

\begin{tabular}{lllll}
\hline Dependent variable & REG & ROA & ROE & ATO \\
\hline C & 0.007002 & -0.021072 & -0.057966 & 0.104588 \\
Coronavirus & $-0.399433^{* * *}$ & $-0.003005^{* * *}$ & $-0.007744^{* * *}$ & $-0.052164^{* * *}$ \\
CC & $0.004927 * * *$ & $0.003433^{* * *}$ & $0.002093 * * *$ & $0.001077^{* * *}$ \\
CSR & $0.002372^{* * *}$ & $0.003412^{* * *}$ & $0.002109^{* * *}$ & $0.015577 * * *$ \\
Liquidity & -0.001560 & $0.002067^{*}$ & $0.001078^{*}$ & -0.000905 \\
CCC & $0.000000^{*}$ & 0.000000 & 0.000000 & $0.000025^{*}$ \\
Capital structure & -0.004837 & $-0.002184^{*}$ & $-0.003275^{*}$ & $-0.004159 * * *$ \\
State ownership & $0.000585^{*}$ & 0.000000 & 0.000000 & 0.000257 \\
Size & 0.001328 & $0.002298^{*}$ & $0.006062^{*}$ & 0.001277 \\
Industry & $0.011199^{*}$ & $0.000371^{*}$ & $0.001141^{*}$ & $-0.003286^{*}$ \\
F-statistics & $86.32963 * * *$ & $22.31128^{* * *}$ & $44.03888^{* * *}$ & $91.45425^{* * *}$ \\
\hline
\end{tabular}

Notes: $* * *$ is 0.01 significance level; $* *$ is 0.05 significance level; $*$ is 0.1 significance level
Overall, the death cases of Coronavirus in different provinces or cities had strong adverse effects on financial performance of Chinese listed companies.

Table 8 provides outcomes of tests for impacts of the Covid-19 outbreak on Chinese firms' financial performance across regions in China. The interaction terms between the Covid-19 outbreak and each region were negative and significant in all models. Notable, these terms were most significant for the central region, so Chinese listed firms in the mid regions experienced the stronger negative impacts of the Coronavirus outbreak on their financial performance than others. Compared with east and west, Hubei, as an important province in Central China, was severely impacted by the outbreak. Overall, Hypothesis 3 was confirmed.

To explore the strongest effects of the Covid-19 pandemic on the central region in China, Table 9 provides outcomes of tests for impacts of the Covid-19 outbreak on firms' financial performance in 6 provinces around the Hubei province, where the outbreak emerged. The interaction terms between the Covid-19 outbreak and DHB were significant and negative, so Chinese listed firms' financial performance around the Hubei province were most severely affected by this outbreak than others.

\section{Moderating Effects-Corporate Culture and Corporate Social Responsibility (CSR)}

Table 10 provides outcomes of tests for the moderating role of corporate culture and CSR for the relationship between the Covid-19 outbreak and Chinese firms' financial performance. In four models, the interaction terms between the Covid-19 outbreak and corporate culture and between the Covid-19 outbreak and CSR were significant and positive, so the moderating role of corporate culture and CSR for the relationship between the Covid-19 outbreak and Chinese firms' financial performance, wherein the Hypotheses 5 and 6, were confirmed. Corporate culture and CSR reduced the negative impacts of the Coronavirus outbreak on Chinese firms' financial performance although such moderating effects were modest (coefficients of the interaction terms were extremely small in four models).

The interactions between this outbreak, the medicine industry, and corporate culture were also added and tested. These interaction terms were significant and positive, so Chinese medical firms with good corporate culture could reduce negative impacts of the Covid-19 outbreak on their financial performance. For ATE industry, when the interaction terms between this industry, the Covid-19 outbreak, and corporate culture was added, coefficients of these terms were significant and positive, so corporate culture could reduce negative impacts of this outbreak on this industry's financial performance. Similarly, CSR was also found to reduce the negative impacts of the Coronavirus outbreak on financial performance of both the medicine and ATE. Nonetheless, the moderating role of corporate culture and CSR for the relationship between the Coronavirus outbreak and the financial performance of firms in these industries was marginal. Moreover, in seriously regions, corporate culture was found to significantly and negatively influenced the negative relationship between the Covid19 outbreak and firms' financial performance. This meant that the corporate culture reduced this negative linkage or Chinese firms in the dangerously seriously risky regions with the better corporate culture would experience the less negative impacts of this outbreak on their financial performance. However, the moderating role of CSR for the negative relationship between the Covid-19 outbreak and firms' financial performance in this region was not confirmed at 0.05 significance level. For the high risky regions, the interaction terms between the Covid-19 outbreak, DHR, and corporate culture and the interaction terms between this outbreak, DHR, and CSR were insignificant and negative in all models. Thus, the moderating role of corporate culture and CSR for the relationship between this outbreak and the financial performance of Chinese listed firms was not confirmed. Specifically, regarding the moderating role of corporate culture and CSR, the interaction terms between these variables, the effects were the most significant for the mid region 
Table 5 Generalized linear regression with medicine \& ATE industry (cross-section weights \& white cross-section covariance method)

\begin{tabular}{|c|c|c|c|c|}
\hline Dependent variable & REG & ROA & ROE & ATO \\
\hline $\mathrm{C}$ & 0.004821 & -0.013052 & -0.066109 & 0.002817 \\
\hline Coronavirus & $-0.009374 * * *$ & $-0.005529 * * *$ & $-0.004138 * * *$ & $-0.005244 * * *$ \\
\hline Medicine & $0.001352 * * *$ & $0.000511 * * *$ & $0.001258 * * *$ & $0.001169 * * *$ \\
\hline Coronavirus*Medicine & $0.004662 * * *$ & $0.001493 * * *$ & $0.001152 * * *$ & $0.001519 * * *$ \\
\hline ATE & $-0.023942 * * *$ & $0.001449 * * *$ & $0.003028 * * *$ & $0.002685 * * *$ \\
\hline Coronavirus*ATE & $-0.014384 * * *$ & $-0.009186^{* * *}$ & $-0.000229 * * *$ & $-0.002356 * * *$ \\
\hline $\mathrm{CC}$ & $0.003284 * * *$ & $0.002458 * * *$ & $0.002173 * * *$ & $0.001592 * * *$ \\
\hline CSR & $0.001092 * *$ & $0.0021817 * *$ & $0.001302 * *$ & $0.008309 * *$ \\
\hline Liquidity & -0.002319 & $0.001173 *$ & $0.001083 *$ & -0.001358 \\
\hline $\mathrm{CCC}$ & $0.000013^{*}$ & 0.000000 & 0.000000 & $-0.000036^{*}$ \\
\hline Capital structure & -0.062169 & $-0.002109^{*}$ & $-0.001752 *$ & -0.252419 \\
\hline State ownership & $-0.001056^{*}$ & 0.000000 & 0.000000 & 0.000107 \\
\hline Size & 0.001263 & $0.001018^{*}$ & $0.001253 *$ & 0.000789 \\
\hline F-statistics & $78.24398 * * *$ & $19.31872 * * *$ & $52.14027 * * *$ & $87.28372 * * *$ \\
\hline
\end{tabular}

Notes: *** is 0.01 significance level; ** is 0.05 significance level; * is 0.1 significance level

in China. The negative coefficient of these interaction terms suggest that corporate culture and CSR would reduce the negative impacts of this outbreak on financial performance of Chinese listed firms in the middle region whereas their moderating role was rejected in others. Lastly, the interaction terms between this outbreak, DHB, and corporate culture as well as between this outbreak, DHB, and CSR were positive and significant. Therefore, corporate culture and CSR can moderate the negative impacts of this outbreak on Chinese firms' financial performance around the Hubei province.

Table 11 provides outcomes of tests for the moderating role of Chinese state-owned listed companies' corporate culture and CSR for the relationship between the Covid-19 outbreak and financial performance. The interaction terms between the state ownership and the Covid-19 outbreak were significant and positive in all models. Thus, the state ownership moderated the relationship between the coronavirus outbreak and Chinese firms' financial performance.
Because of the positive coefficients of interaction terms, the state ownership reduced the degree of negative effects of this outbreak on Chinese firms' financial performance (Wooldridge, 2015). In the other words, SOEs experienced fewer negative effects of the coronavirus outbreak on their financial performance than non-SOEs. Regarding the moderating effects of corporate culture and CSR, the interaction terms between these variables, the Coronavirus outbreak, and DSO were positive and significant in all models. Therefore, the corporate culture and CSR can moderate the relationship between this outbreak and Chinese SOEs and non-SOE's financial performance.

\section{Discussion}

This study revealed that the Coronavirus outbreak reduced the financial performance of Chinese listed firms since their revenue growth rate, $\mathrm{ROA}, \mathrm{ROE}$, and asset turnover
Table 6 Generalized linear regression in Serious Regions (cross-section weights \& white cross-section covariance method)

\begin{tabular}{lllll}
\hline Dependent variable & REG & ROA & ROE & ATO \\
\hline C & 0.002923 & -0.082392 & -0.012693 & -0.001927 \\
Coronavirus & $-0.004335 * * *$ & $-0.003532 * * *$ & $-0.002245 * * *$ & $-0.003544 * * *$ \\
DSR & $-0.001432 * *$ & $-0.001930 * *$ & $-0.002804 * *$ & $-0.001082 * *$ \\
Coronavirus*DSR & $-0.003193 * * *$ & $-0.002291 * * *$ & $-0.002192 * * *$ & $-0.004138 * * *$ \\
CC & $0.002720 * * *$ & $0.001933 * * *$ & $0.001381 * * *$ & $0.001318 * * *$ \\
CSR & $0.001752 * *$ & $0.001429 * *$ & $0.001093 * *$ & $0.001029 * *$ \\
Liquidity & -0.002260 & $0.001072 *$ & $0.001108 *$ & -0.003025 \\
CCC & $-0.000902 *$ & -0.004072 & 0.000000 & $-0.000712 *$ \\
Capital structure & -0.001933 & $-0.001651 *$ & $-0.001523 *$ & -0.000492 \\
State ownership & $-0.001923 *$ & 0.000000 & 0.000000 & 0.000000 \\
Size & 0.002837 & $0.000184 *$ & $0.001224 *$ & 0.003717 \\
Industry & $0.000142 *$ & $0.003121 *$ & $0.002901 *$ & $-0.001533 *$ \\
F-statistics & $96.44512 * * *$ & $35.82471 * * *$ & $47.90162 * * *$ & $95.24629 * * *$ \\
\hline
\end{tabular}

Notes: $* * *$ is 0.01 significance level; $* *$ is 0.05 significance level; $*$ is 0.1 significance level 
dropped significantly in the first quarter of 2020 after the control for firms' unique characteristics and industry's specific factors. Therefore, the first hypothesis (H1) is confirmed. The negative effects of this outbreak on Chinese listed firms' financial performance can be justified by the disruptions of Chinese firms' supply chains and operations caused by the quarantine and the increase of costs associated with this outbreak responses (i.e., additional costs incurred for quarantine and workforce protection, the higher transportation and logistics costs) (Fernandes, 2020). However, except the huge impacts on the revenue growth rate, the negative impacts of the Coronavirus outbreak on ROA, ROE, and asset turnover were modest with just $0.3 \%, 0.08 \%$, and $5.2 \%$, respectively. These humble effects of the Coronavirus outbreak on Chinese firms' financial performance could be justified by several reasons.

According to Narayandas et al. (2020), Chinese firms quickly leveraged their digital technologies, so they could adapt quickly to change caused by this outbreak and innovate their business' model and strategies to response to this outbreak. They utilised the virtual video meetings to communicate with employees effectively, empowered the regional frontline employees to address the disruptions of supply chains, and implemented the innovative initiatives that enabled them to go through challenges caused by this outbreak effectively. For example, Yili Group allowed the regional frontline employees to make decisions to address unexpected problems during the closedown such as roadblocks, health checks for drivers, and community shutdowns. Consequently, its supply chain' smooth operations, even in the remote areas, could be assured. Huanxi Media Group decided to livestream the movie "Lost in Russia" and other content after the close of their movie theatres. Therefore, it could earn \$91 million from this movie and still reached 600 million views within 2 days. Trip.com Group built the agile teams to quickly response to travel plan cancels while maintaining customer satisfaction, etc.
To strengthen their resilience, Chinese listed firms also redefined their models for the collaboration and teamwork by changing the performance evaluation system, promoting knowledge sharing, and offering online training activities for their employees. With such initiatives, Chinese listed firms could mitigate the negative impacts of the Coronavirus outbreak on their financial performance although their revenue declined significantly.

Findings on negative impacts of the Coronavirus outbreak on Chinese listed firms' financial performance figured out in this study, hence, align with findings on the negative impacts of this crisis on the financial and non-financial performance of Nigerian firms of Aifuwa et al. (2020). However, this study's findings differ from findings of Secinaro et al. (2020) since these scholars indicated that dangerously contagious diseases like 2003 SARS did not severely influence the financial performance of travel firms. The difference between this study and Secinaro et al. (2020) can be justified by the research methods employed by two studies. Secinaro et al. (2020) studied impacts of the 2003 SARS on firms' financial performance based on annual data whereas this disease was controlled within the first six months of the year of 2003. Therefore, the annual data might dilute impacts of this disease. Differently, this study just focused on the first quarter performance of Chinese listed firms, which marked the emergence and spread of the Coronavirus outbreak. Thus, the dilution of impacts of this outbreak on financial performance of firms did not occur.

Like Jung et al. (2016) and Hassan et al. (2020), this study revealed that impacts of the Coronavirus outbreak on Chinese listed firms' financial performance are not homogenous or the second hypothesis (H2) is confirmed. Such impacts varied across firms and industries, suggesting that firms' unique characteristics and their industry's specific factors moderated their performance under the negative impacts of this outbreak. Since the coefficients of the interaction terms between the
Table 7 Generalized linear regression in High-Risky Regions (cross-section weights \& White cross-section covariance method)

\begin{tabular}{lllll}
\hline Dependent variable & REG & ROA & ROE & ATO \\
\hline C & 0.001038 & 0.018164 & $-0.012264^{*}$ & -0.0031527 \\
Coronavirus & $-0.045867^{* * *}$ & $-0.006243^{* * *}$ & $-0.072545^{* * *}$ & $-0.005436^{* * *}$ \\
DHR & $-0.008682^{* *}$ & $-0.004853^{* *}$ & $-0.004421^{* *}$ & $-0.001488^{* *}$ \\
Coronavirus*DHR & $-0.005859^{* * *}$ & $0.004915^{* * *}$ & $0.004926^{* * *}$ & $0.005387^{* * *}$ \\
CC & $0.003120^{* * *}$ & $0.002384^{* * *}$ & $0.002819^{* * *}$ & $0.002072^{* * *}$ \\
CSR & $0.001942^{*}$ & $0.001209^{*}$ & $0.002247^{*}$ & $0.001529 *$ \\
Liquidity & -0.001930 & $0.002742^{*}$ & $0.000450^{*}$ & -0.000556 \\
CCC & $-0.001134 *$ & -0.001787 & -0.002452 & $-0.001249^{*}$ \\
Capital structure & -0.000133 & $-0.000329^{*}$ & $-0.002246^{*}$ & -0.001397 \\
State ownership & $-0.002019 *$ & -0.001292 & 0.000329 & 0.002417 \\
Size & 0.001324 & $0.000412^{*}$ & $0.000412^{*}$ & 0.000513 \\
Industry & $0.002146^{*}$ & $0.002301^{*}$ & $0.003945^{*}$ & $0.005436^{*}$ \\
F-statistics & $97.43421^{* * *}$ & $39.98565^{* * *}$ & $58.26957^{* * *}$ & $95.67289^{* * *}$ \\
\hline
\end{tabular}

Notes: $* * *$ is 0.01 significance level; $* *$ is 0.05 significance level; $*$ is 0.1 significance level 
Table 8 Generalized linear regression in China's Different Zones (cross-section weights \& white cross-section covariance method)

\begin{tabular}{|c|c|c|c|c|}
\hline Dependent variable & REG & ROA & ROE & ATO \\
\hline $\mathrm{C}$ & 0.002453 & 0.002454 & 0.004549 & 0.001782 \\
\hline Coronavirus & $-0.003428 * * *$ & $-0.002143^{* * *}$ & $-0.001334 * * *$ & $-0.002446^{* * *}$ \\
\hline Coast & $-0.001342 *$ & $-0.001729^{*}$ & $-0.001533^{*}$ & $-0.001619^{*}$ \\
\hline Coronavirus*East & $-0.002817^{*}$ & $-0.003569^{*}$ & $-0.002926^{*}$ & $-0.002871^{*}$ \\
\hline Mid & $-0.000938 * *$ & $-0.000193 * *$ & $-0.00184 * *$ & $-0.000748^{* *}$ \\
\hline Coronavirus*Central & $-0.002342 * *$ & $-0.001239 * *$ & $-0.001286^{* *}$ & $-0.002394 * *$ \\
\hline West & $-0.000221 *$ & $-0.000185^{*}$ & $-0.000153^{*}$ & $-0.000169^{*}$ \\
\hline Coronavirus*West & $-0.001329^{*}$ & $-0.000928 *$ & $-0.000712 *$ & $-0.001895^{*}$ \\
\hline $\mathrm{CC}$ & $0.001668 * * *$ & $0.001367 * * *$ & $0.001768 * * *$ & $0.001352 * * *$ \\
\hline CSR & $0.000832 *$ & $0.000287 *$ & $0.000432 * *$ & $0.000513 * *$ \\
\hline Liquidity & -0.003228 & $0.001039 *$ & $0.001543 *$ & -0.001457 \\
\hline $\mathrm{CCC}$ & $-0.000352 *$ & -0.00239 & -0.001325 & $-0.000847^{*}$ \\
\hline Capital structure & -0.001029 & $-0.001028^{*}$ & $-0.001392^{*}$ & $-0.000869^{*}$ \\
\hline State ownership & $-0.002329^{*}$ & -0.001918 & -0.001303 & -0.001836 \\
\hline Size & 0.001129 & $0.001348^{*}$ & $0.001980 *$ & 0.001762 \\
\hline Industry & $0.000136^{*}$ & $0.000424 *$ & $0.001337 *$ & $0.001928^{*}$ \\
\hline F-statistics & $128.39173 * * *$ & $61.29183 * * *$ & $69.42754 * * *$ & $96.30183 * * *$ \\
\hline
\end{tabular}

Notes: $* * *$ is 0.01 significance level; ** is 0.05 significance level; $*$ is 0.1 significance level

coronavirus outbreak and industry were positive in all models, the industry variable made the negative effects of coronavirus on financial performance of Chinese listed firms stronger for several industries - Travel and Leisure, Healthcare, Basic Materials, etc. whereas two others - Technology and Paper production experienced the least negative effects from this outbreak. Travel and Leisure suffered most since this sector was the service-oriented sector, so travel restrictions plunged their revenue (Fernandes, 2020). The severe impacts of this outbreak on the healthcare industry can be justified by the significant investment of these firms to accommodate customer demands for healthcare products. Basic materials industry was also severely affected by this outbreak since the disruption of supply chains and the reduction of industrial outputs shrank this industry's revenue and profit (Bloomberg, 2020). By contrast, the technology industry was least influenced by this outbreak since the outbreak created business opportunities for them and with their business nature, they could switch their operations online easily (Narayandas et al., 2020). The less negative impacts of the Coronavirus outbreak on the paper production industry can be explained by the fact that this industry experienced the soaring demands for several products such as toilet paper and other hygienic products (PwC, 2020).
Table 9 Generalized linear regression in Hubei Effects (cross-section weights \& White cross-section covariance method)

\begin{tabular}{lllll}
\hline Dependent variable & REG & ROA & ROE & ATO \\
\hline C & 0.001244 & -0.001048 & -0.002693 & -0.001257 \\
Coronavirus & $-0.004351^{* * *}$ & $-0.002538^{* * *}$ & $-0.002713^{* * * *}$ & $-0.000144^{* * *}$ \\
DHB & $-0.000676^{* *}$ & $-0.000530^{* *}$ & $-0.000354 * *$ & $-0.00472^{* *}$ \\
Coronavirus*DHB & $-0.005134^{* * *}$ & $-0.003976^{* * *}$ & $-0.002628^{* * *}$ & $-0.004751^{* * *}$ \\
CC & $0.000385^{* *}$ & $0.000279^{* *}$ & $0.000281^{* *}$ & $0.000298^{* *}$ \\
CSR & $0.000152^{*}$ & $0.000169^{*}$ & $0.000193^{*}$ & $0.0000129 *$ \\
Liquidity & -0.001926 & $0.001123^{*}$ & $0.001186^{*}$ & -0.001174 \\
CCC & $-0.001134^{*}$ & -0.001422 & -0.002242 & $-0.001327 *$ \\
Capital structure & -0.002681 & $-0.001917^{*}$ & $-0.001638^{*}$ & -0.002438 \\
State ownership & $-0.000334^{*}$ & 0.00223 & 0.000192 & 0.000539 \\
Size & 0.002431 & $0.001354^{*}$ & $0.000847 *$ & 0.001182 \\
Industry & $0.001432^{*}$ & $0.000893^{*}$ & $0.000713^{*}$ & $0.000533^{*}$ \\
F-statistics & $99.83116^{* * *}$ & $58.64263^{* * *}$ & $53.03872^{* * *}$ & $97.34183 * * *$ \\
\hline
\end{tabular}

Notes: $* * *$ is 0.01 significance level; $* *$ is 0.05 significance level; * is 0.1 significance level 
Table 10 Generalized linear regression with CR and CSR (cross-section weights \& white cross-section variance method)

\begin{tabular}{|c|c|c|c|c|}
\hline Dependent variable & REG & ROA & ROE & ATO \\
\hline $\mathrm{C}$ & 0.001426 & -0.001048 & -0.001423 & -0.001374 \\
\hline Coronavirus & $-0.002314 * * *$ & $-0.001258 * * *$ & $-0.001353 * * *$ & $-0.001685^{* * *}$ \\
\hline $\mathrm{CC}$ & $0.002382 * * *$ & $0.001349 * * *$ & $0.001831 * * *$ & $0.001991 * * *$ \\
\hline Coronavirus*CC & $0.000120 * * *$ & $0.000096^{* * *}$ & $0.000104 * * *$ & $0.000112 * * *$ \\
\hline CSR & $0.001228 * *$ & $0.001029 * *$ & $0.001038^{*}$ & $0.0000129^{*}$ \\
\hline Coronavirus*CSR & $0.000082 *$ & $0.000043^{*}$ & $0.000035^{*}$ & $0.000057^{*}$ \\
\hline Coronavirus*Medicine*CC & $0.008230 * * *$ & $0.005282 * * *$ & $0.004982 * * *$ & $0.005872 * * *$ \\
\hline Coronavirus*ATE*CC & $0.006831 * *$ & $0.004338 * *$ & $0.003281 * *$ & $0.004482 * *$ \\
\hline Coronavirus*DSR $* \mathrm{CC}$ & $-0.000827 * *$ & $-0.000429 * *$ & $-0.000381 * *$ & $-0.000608 * *$ \\
\hline Coronavirus*DHR*CC & $-0.001182 *$ & $-0.001093 *$ & $-0.000812^{*}$ & $-.0001042^{*}$ \\
\hline Coronavirus*East*CC & $-0.000128^{*}$ & $-0.000127^{*}$ & $-0.000138^{*}$ & $-0.000192^{*}$ \\
\hline Coronavirus*Central ${ }^{*} \mathrm{CC}$ & $-0.003621 * *$ & $-0.001823 * *$ & $-0.001338^{* *}$ & $-0.002142 * *$ \\
\hline Coronavirus*West*CC & $-0.000372 *$ & $-0.000239 *$ & $-0.000216^{*}$ & $-0.000182^{*}$ \\
\hline Coronavirus*DHB*CC & $0.000225^{*}$ & $0.000142^{*}$ & $0.000129 *$ & $0.000231^{*}$ \\
\hline Coronavirus*Medicine*CSR & $0.002982 * *$ & $0.002392 * *$ & $0.002426 * *$ & $0.001093 * *$ \\
\hline Coronavirus*ATE*CSR & $0.002938^{*}$ & $0.002178^{*}$ & $0.001982 *$ & $0.000128^{*}$ \\
\hline Coronavirus*DSR $* \mathrm{CSR}$ & $-0.000292 *$ & $-0.000224 *$ & $-0.000183^{*}$ & $-0.000198^{*}$ \\
\hline Coronavirus*DHR*CSR & $-0.000394 *$ & $-0.000242^{*}$ & $-0.000221^{*}$ & $-0.000128^{*}$ \\
\hline Coronavirus*East*CSR & $-0.000117 *$ & $-0.000087^{*}$ & $-0.000079^{*}$ & $-0.000126^{*}$ \\
\hline Coronavirus $*$ Central ${ }^{*} \mathrm{CSR}$ & $-0.000382 * *$ & $-0.000212 *$ & $-0.000192^{*}$ & $-0.000223^{* *}$ \\
\hline Coronavirus*West*CSR & $-0.000115^{*}$ & $-0.000098^{*}$ & $-0.000079^{*}$ & $-0.000143^{*}$ \\
\hline Coronavirus*DHB*CSR & $0.000213^{*}$ & $0.000168^{*}$ & $0.000192 *$ & $0.000179^{*}$ \\
\hline Liquidity & -0.000382 & $0.000283^{*}$ & $0.000155^{*}$ & -0.002564 \\
\hline $\mathrm{CCC}$ & $-0.000313^{*}$ & -0.002556 & -0.001426 & $-0.000455^{*}$ \\
\hline Capital structure & -0.002861 & $-0.000496^{*}$ & $-0.000835^{*}$ & -0.002863 \\
\hline State ownership & $-0.000230^{*}$ & 0.000289 & 0.000232 & 0.000736 \\
\hline Size & 0.000134 & $0.000692^{*}$ & $0.000324 *$ & 0.000122 \\
\hline F-statistics & $129.82463 * * *$ & $82.98143 * * *$ & $86.82736^{* * *}$ & $117.98133 * * *$ \\
\hline
\end{tabular}

Notes: $* * *$ is 0.01 significance level; ** is 0.05 significance level; $*$ is 0.1 significance level

Furthermore, this study revealed that firms with the conservative working capital management strategy could mitigate impacts of Coronavirus on their performance since these firms could adapt quickly to customers' demands (Afza \& Nazir, 2007), especially in the context of the disruption of supply chains caused by the strict quarantines (Ivanov \& Das, 2020). Firms with the high degree of financial leverage suffered more from this outbreak since they incurred a large interest expense burdens (Myers, 1984) while revenue declined. Firms with larger size could also obtain economies of scale (Stigler, 1958) to mitigate impacts of this outbreak on their profitability and asset turnover.

Regarding to the moderating role of corporate culture and CSR, this study found that in general corporate culture and CSR reduced negative impacts of the Covid-19 outbreak on Chinese firms' financial performance, which has confirmed the $\mathrm{H} 4$ and $\mathrm{H} 5$. However, such moderating role did not appear consistently for all firms, which were classified by industry and regions. For dangerously highly risky region, the corporate culture and CSR did not help to reduce negative impacts of the Covid-19 outbreak on firms' financial performance whereas for the dangerously serious risky region, corporate culture and CSR could reduce such negative impacts. When firms were classified by state ownership, the moderating role of corporate culture and CSR were just confirmed at $10 \%$ significance level.

Lastly, this study has revealed that state ownership moderated the relationship between the coronavirus and financial performance of Chinese listed firms, which has confirmed the H6. Since the interaction terms between the coronavirus outbreak and state ownership were positive, the state ownership reduced the magnitude of negative effects of this outbreak on Chinese listed firms' financial performance. In the other words, the revenue growth rate, ROA, ROE, and asset turnover of SOEs suffered less from this outbreak than others. This finding could be justified by the fact that SOEs always get more supports from Chinese government than non-SOEs (Li et al., 2014). Therefore, they can perform better than non-SOEs due to such supports. 
Table 11 Generalized linear regression in State-ownership List Companies (cross-section weights \& White cross-section covariance method)

\begin{tabular}{|c|c|c|c|c|}
\hline Dependent variable & REG & ROA & ROE & ATO \\
\hline $\mathrm{C}$ & 0.027817 & $-0.022708 * * *$ & $-0.056606^{* * *}$ & $0.108270 * * *$ \\
\hline Coronavirus & $-0.003135^{* * *}$ & $-0.002306^{* * *}$ & $-0.002418^{* * *}$ & $-0.003216^{* * *}$ \\
\hline DSO & $0.000343 * * *$ & $0.000221 * * *$ & $0.000127 * * *$ & $0.000259 * * *$ \\
\hline Coronavirus*DSO & $0.001431 * * *$ & $0.001325 * * *$ & $0.001164 * * *$ & $0.001273 * * *$ \\
\hline $\mathrm{CC}$ & $0.000832 * * *$ & $0.000563 * * *$ & $0.000329 * * *$ & $0.000664 * * *$ \\
\hline Coronavirus*DSO*CC & $0.000272 *$ & $0.000118 *$ & $0.000105^{*}$ & $0.000198 *$ \\
\hline CSR & $0.000629 * *$ & $0.000483 * *$ & $0.000276^{* *}$ & $0.000489 * *$ \\
\hline Coronavirus*DSO $* \mathrm{CSR}$ & $0.000517 *$ & $0.000386^{*}$ & $0.000281 *$ & $0.000392 *$ \\
\hline Liquidity & -0.001323 & $0.001124 *$ & $0.001273^{*}$ & -0.009049 \\
\hline $\mathrm{CCC}$ & $-9.05 \mathrm{E}-05^{*}$ & $-4.04 \mathrm{E}-07$ & $2.48 \mathrm{E}-07$ & $-2.78 \mathrm{E}-06^{*}$ \\
\hline Capital structure & -0.084562 & $-0.001925^{*}$ & $-0.001341^{*}$ & -0.251720 \\
\hline Size & 0.002324 & 0.002461 & 0.005835 & 0.015371 \\
\hline Industry & $0.001513 *$ & $0.001288^{*}$ & $0.001088^{*}$ & $0.001565^{*}$ \\
\hline F-statistics & $155.7781 * * *$ & $21.30743 * * *$ & $46.73687 * * *$ & $72.72873 * * *$ \\
\hline
\end{tabular}

Notes: $* * *$ is 0.01 significance level; ** is 0.05 significance level; $*$ is 0.1 significance level

\section{Conclusion and Policy Implementation}

With an aim to examine impacts of the Coronavirus outbreak on Chinese listed firms' financial performance, this study collected the quarterly financial data of Chinese listed firms from 16 industries and applied the GLS with cross-section weights, using White cross-section covariance method (McManus, 2015) to test developed hypotheses.

This study figured out that the Coronavirus outbreak negatively affected Chinese listed firms' financial performance since their revenue growth rates, ROA, ROE, and asset turnover ratio declined significantly in the quarter of this outbreak impact after controlling for firms' unique characteristics and industry's specific factors. Nonetheless, except the huge decline of the revenue growth rate (approximately 40\%) caused by the Coronavirus outbreak, impacts of this outbreak on the remaining indicators of firm's performance were modest with $0.3 \%, 0.8 \%$, and $5.2 \%$ for ROA, ROE, and asset turnover, respectively. Thus, the magnitude of the negative effects of this outbreak on Chinese firms' financial performance proxied by profitability and asset turnover ratio was not as high as expected. These mild negative effects of this outbreak on Chinese firms' financial performance can be justified by several good practices of Chinese firms to deal with this outbreak (i.e., the leveraging digital technologies, the transformation of business models, the empowerment of its people, and the redefinition of their operations and teamwork) (Narayandas et al., 2020).

On the other hand, this study revealed that in the context of the Coronavirus outbreak, Chinese firms with the conservative working capital management strategy experienced the higher degree of negative impacts of this outbreak on their revenue growth rate and asset turnover but experienced the lower degree of negative impacts of this outbreak on their profitability due to their ability to response quickly to customer's demand (Afza \& Nazir, 2007). Firms with the high degree of financial leverage experienced the lower firm performance due to the high interest burdens (Myers, 1984) while revenue and profit decline. Firms with the larger size experienced the higher ROA, ROE, and asset turnover due to both economies of scale (Stigler, 1958) and the large customer base benefits (Josefy et al., 2015). Firms with the state ownership suffered less from the negative impacts of the coronavirus outbreak on their ROA, ROE, and asset turnover. Impacts of this outbreak on Chinese firms' performance also varied across industries. When other factors were controlled, Travel and Leisure industry experienced the highest revenue decline, highest ROA, and ROE decline, followed by Retailer, Healthcare, and Basic materials. By contrast, other industries such as Technology, Paper production, etc. experienced the lowest revenue decline and the lowest ROA and ROE decline. In terms of asset turnover, the ability in generating revenue from assets of the Travel and Leisure, Retailer, Healthcare, and Basic materials was highest whereas this ability was lowest for Technology, Paper production, etc. This study have also confirmed the heterogenous impacts of CSR on financial performance of Chinese listed firms in different industries, regions, and ownerships. The moderating roles of corporate culture and CSR have confirmed for the impacts of Covid-19 pandemic on Chinese listed firms' performance in most cases.

Despite this study's achievement, as well as its significant contribution to the literature, this study still contains two main limitations. Firstly, it involves 16 industries represented for Chinese listed firms. This means that there are some minor 
sectors that were not included in the study. Although this limitation does not severely affect the study's outcome, it is still a limitation that should be aware. Secondly, since earnings management is a critical accounting problem (Healy \& Wahlen, 1999), it may happen when Chinese listed firms report their quarterly data. Therefore, this study's outcome may be affected by the degree of earnings management engaged by Chinese listed firms, especially since the Chinese market transparency is not as high as developed countries (Cheung et al., 2010).

Findings of this study suggest several helpful implications associated with changes in business strategies as responses to dangerously contagious diseases for practitioners. In the context of the contagious outbreaks, firms need to adopt the conservative working capital management strategy instead of the aggressive working capital management strategy since this strategy enables firms to response quickly to customer's demands (Afza \& Nazir, 2007). The outbreak can create fear, inducing unmoral customer behaviours such as speculations of necessary goods for the uncertain future (Nicola et al., 2020). Therefore, without the high level of inventories, firms may not adapt well with customers' demands, leading to the reduction of their profitability and asset turnover ratio. The conservative working capital management strategy also works in the context of the supply chain disruptions caused by the health crisis (Fernandes, 2020; Ivanov \& Das, 2020). On the other hand, firms need to determine their optimal capital structure; examine investment projects

Table 12 Raw Variables of CSR and Corporate Culture carefully; and develop contingent plans for the crisis context. The overuse of debts can reduce their profitability during this crisis, especially when revenue declines and interest expenses are substantial. Furthermore, innovation, communication improvement, and transformation of business models are also needed for firms to go through crisis effectively and improve their resilience (Narayandas et al., 2020). The development of corporate culture and CSR is essential for firms to response to crises like this pandemic, as well.

For academicians, the continuous examination of impacts of the Coronavirus outbreak on firms' financial performance using later releasing data (i.e., interim reports and annual reports) is essential to provide the more comprehensive picture on such impacts. Academicians can compare impacts of this outbreak on the financial performance of Chinese listed firms at their different lifecycles since such findings are helpful for practitioners to develop their business strategies to deal with future outbreaks. Furthermore, the study on differences in impacts of Coronavirus outbreak on financial and market performance of firms is also necessary to figure out deviation of market performance from financial performance in the context of fear caused by this health crisis.

\section{Appendices}

\begin{tabular}{ll}
\hline CSR Categories & Variables \\
Responsibility to the government & Main business taxes and surcharges/Main business income \\
& Total income tax / total profit \\
Responsibility to employees & Total amount paid to and for employees/Total revenue from main business \\
Responsibility to shareholders & Dividend/earnings per share \\
Responsibility to creditors & $1 /$ asset liability ratio \\
& Quick assets / current liabilities \\
(main business cost + ending inventory - opening inventory) / & average accounts payable \\
Responsibility to suppliers & Cash paid for purchasing goods and accepting services/Total \\
& revenue from main business \\
& Main business cost / main business income \\
Responsibility to customers & Variables \\
Corporate culture Categories & Main business taxes and surcharges/Main business income \\
Responsibility to the government & Total income tax / total profit \\
& Total amount paid to and for employees/Total revenue from main business \\
Responsibility to employees & Dividend/earnings per share \\
Responsibility to shareholders & $1 /$ asset liability ratio \\
Responsibility to creditors & Quick assets / current liabilities \\
& (main business cost + ending inventory - opening inventory) / \\
Responsibility to suppliers & average accounts payable \\
& Cash paid for purchasing goods and accepting services/Total \\
& revenue from main business \\
Responsibility to customers & Main business cost / main business income
\end{tabular}

CSR Categories Responsibility to shareholders

Responsibility to suppliers

Responsibility to customers Corporate culture Categories ensibility to the government

to employees Responsibility to shareholders

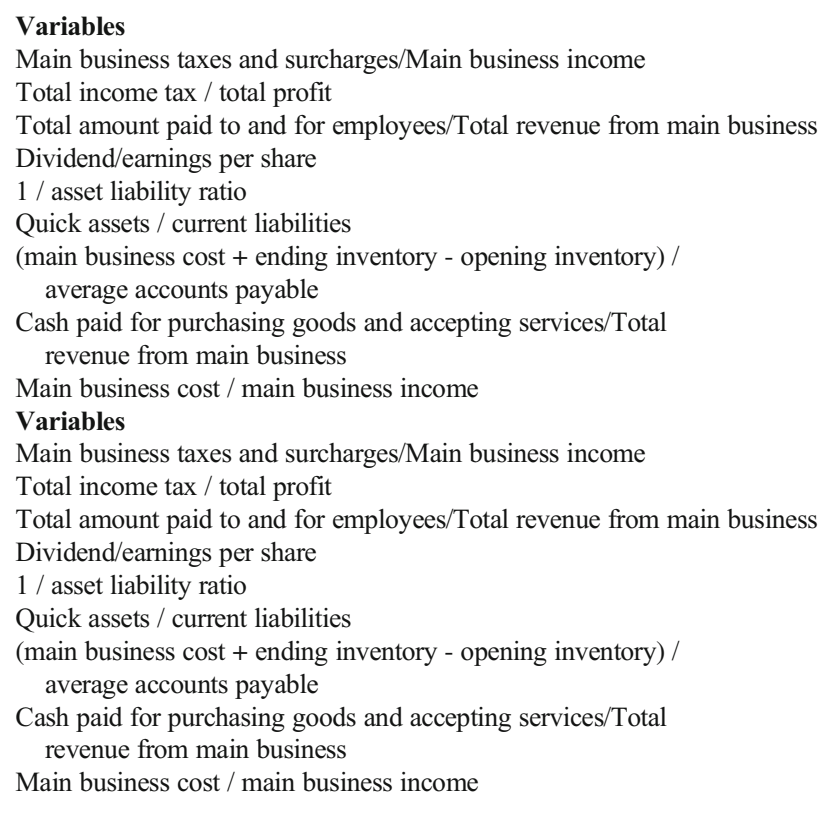


Acknowledgements The authors acknowledge the financial support from the Philosophy \& Social Science Fund of Tianjin City, China (Project No. TJYJ20-012).

Authors' Contribution All authors contributed equally in this work.

Funding This research was supported by The Philosophy \& Social Science Fund of Tianjin City, China (Grant No. TJYYQN20-012).

Data Availability All results reported in this research was carried out in Rstudio computational environment.

Data used in this research is taken from Wind-Economic Database from the second quarter of the year of 2019 to the second quarter of the year of 2020 available online at:

https://www.wind.com.cn/en/edb.html

\section{Declarations}

Ethics Approval and Consent to Participate This article does not contain any studies with human participants or animals performed by any of the authors.

Competing Interests The author declares no competing interest.

Conflict of Interest None.

\section{References}

Afza, T., \& Nazir, M. (2007). Is it better to be aggressive or conservative in managing working capital. Journal of Quality and Technology Management, 3(2), 11-21.

Aifuwa, H. O., Saidu, M., \& Aifuwa, S. A. (2020). Coronavirus outbreak outbreak and firms performance in Nigeria. Management and Human Resources Research.

Alber, N. (2020). The effect of coronavirus spread on stock markets: The case of the worst 6 countries. MUFIDER, 3(1), 78-84.

Ali, M., Alam, N., \& Rizvi, S. (2020). Coronavirus (COVID-19)-an epidemic or outbreak for financial markets. Journal of Behavioural and Experimental Finance, 27, 100341.

Altig, D., Baker, S., Barrero, J. M., Bloom, N., Bunn, P., Chen, S., ... \& Thwaites, G. (2020). Economic uncertainty before and during the COVID-19 pandemic. Journal of Public Economics, 191, 104274.

Arogyaswamy, B., \& Byles, C. (1987). Organizational culture: Internal and external fits. Journal of Management, 13(4), 647-658.

Arora, A., \& Sharma, C. (2016). Corporate governance and firm performance in developing countries: Evidence from India. Corporate Governance, 16(2), 420-436.

Asteriou, D., \& Hall, S. (2015). Applied econometrics. Macmillan International Higher Education.

Baker, M., \& Wurgler, J. (2007). Investor sentiment in the stock market. Journal of Economic Perspectives, 21(2), 129-152.

Baysal, E., Çetin, M., Yaylak, B., Altntas, B., Altndag, R., Adyaman, S., ... \& Sevuk, U. (2015). Roles of the red cell distribution width and neutrophil/lymphocyte ratio in predicting thrombolysis failure in patients with an ST-segment elevation myocardial infarction. Blood Coagulation \& Fibrinolysis, 26(3), 274-278.

Becchetti, L., Di Giacomo, S., \& Pinnacchio, D. (2008). Corporate social responsibility and corporate performance: Evidence from a panel of US listed companies. Applied Economics, 40(5), 541-567.

Bhagat, S., \& Bolton, B. (2008). Corporate governance and firm performance. Journal of Corporate Finance, 14(3), 257-273.
Bird, R., Hall, A., Momentè, F., \& Reggiani, F. (2007). What corporate social responsibility activities are valued by the market? Journal of Business Ethics, 76(2), 189-206.

Bloomberg, 2020. China's Economy Suffers Historic Slump Due to Virus Shutdown. [Online] Available at: https://www.bloomberg.com news/articles/2020-03-16/china-manufacturing-and-retail-contractfor-first-time-on-virus. Accessed 13 July 2020.

Bowen, H. R. (1953). Social responsibilities of the businessman. Harper \& Row.

Bryman, A., \& Bell, E. (2015). Business research methods. Oxford University Press.

Buallay, A., Hamdan, A., \& Zureigat, Q. (2017). Corporate governance and firm performance: Evidence from Saudi Arabia. Australasian Accounting, Business and Finance Journal, 11(1), 78-98.

Cheung, Y., Jiang, P., \& Tan, W. (2010). A transparency disclosure index measuring disclosures: Chinese listed companies. Journal of Accounting and Public Policy, 29(3), 259-280.

Chi, C., \& Gursoy, D. (2009). Employee satisfaction, customer satisfaction, and financial performance: An empirical examination. International Journal of Hospitality Management, 28(2), 245-253.

Christensen, C. M. (1997). Marketing strategy: learning by doing. Harvard business review, 75(6), 141-151.

Davis, K. (1960). Can business afford to ignore social responsibilities? California Management Review, 2(3), 70-76.

Davis, K. (1967). Understanding the social responsibility puzzle. Business Horizons, 10(4), 45-50.

Davis, K. (1973). The case for and against business assumption of social responsibilities. Academy of Management Journal, 16(2), 312-322.

Deloof, M. (2003). Does working capital management affect profitability of Belgian firms? Journal of Business Finance \& Accounting, 30(34), $573-588$

Denison, D. (1990). Corporate culture and organizational effectiveness. John Wiley \& Sons.

Donadelli, M., Kizys, R., \& Riedel, M. (2017). Dangerous infectious diseases: Bad news for Main street, good news for Wall Street. Journal of Financial Markets, 35, 84-103.

Edmans, A. (2012). The link between job satisfaction and firm value, with implications for corporate social responsibility. Academy of Management Perspectives, 26(4), 1-19.

Fernandes, N. (2020). Economic effects of coronavirus outbreak (COVID-19) on the world economy. Available at SSRN 3557504.

Flamholtz, E., \& Kannan-Narasimhan, R. (2005). Differential impact of cultural elements on financial performance. European Management Journal, 23(1), 50-64.

Freeman, R., et al. (2010). Stakeholder theory: The state of the art. Cambridge University Press.

Friedman, M. (1970). A Friedman doctrine: The social responsibility of business is to increase its profits. The New York Times Magazine, 13(1970), 32-33.

Fu, L., Singhal, R., \& Parkash, M. (2016). Tobin's q ratio and firm performance. International Research Journal of Applied Finance, 7(4), $1-10$.

Garanina, T., \& Kaikova, E. (2016). Corporate governance mechanisms and agency costs: Cross-country analysis. Corporate Governance, 16(2), 347-360.

Garriga, E., \& Melé, D. (2004). Corporate social responsibility theories: Mapping the territory. Journal of Business Ethics, 53(1-2), 51-71.

Goh, B., 2020. Lockdown lifted; Wuhan's residence committees keep watch. [Online] Available at: https://www.reuters.com/article/ushealth-coronavirus-china-wuhan/lockdown-lifted-wuhansresidence-committees-keep-watch-idUSKCN21Y0ET. Accessed 13 July 2020.

Hansen, G., \& Wernerfelt, B. (1989). Determinants of firm performance: The relative importance of economic and organizational factors. Strategic Management Journal, 10(5), 399-411. 
Hassan, T. A., Hollander, S., Van Lent, L., Schwedeler, M., \& Tahoun, A. (2020). Firm-level exposure to epidemic diseases: Covid-19, SARS, and H1N1. National Bureau of Economic Research, Issue w26971.

Healy, P., \& Wahlen, J. (1999). A review of the earnings management literature and its implications for standard setting. Accounting Horizons, 13(4), 365-383.

Homburg, C., \& Pflesser, C. (2000). A multiple layer model of market oriented organizational culture: measurementissues and performance outcomes. Journal of Marketing Research, 37, 449-462.

Hsiao, C. (2014). Analysis of panel data. Cambridge University Press.

Huhtala, M., Kangas, M., Lämsä, A., \& Feldt, T. (2013). Ethical managers in ethical organisations? The leadership-culture connection among Finnish managers. Leadership and Organization Development Journal, 34(3), 250-270.

IMF. (2020). Remarks by IMF Managing Director Kristalina Georgieva to G20 on Economic Impact of COVID-19. [Online] Available at: https://www.imf.org/en/News/Articles/2020/02/22/pr2061 remarks-by-kristalina-georgieva-to-g20-on-economic-impact-ofcovid-19. Accessed 12 July 2020.

Ivanov, D., \& Das, A. (2020). Coronavirus (COVID-19/SARS-CoV-2) and supply chain resilience: A research note. International Journal of Integrated Supply Management, 13(1), 90-102.

Jensen, M. (1986). Agency costs of free cash flow, corporate finance, and takeovers. The American Economic Review, 76(2), 323-329.

Jensen, M., \& Meckling, W. (1976). Theory of the firm: Managerial behavior, agency costs and ownership structure. Journal of Financial Economics, 3(4), 305-360.

Josefy, M., Kuban, S., Ireland, R., \& Hitt, M. (2015). All things great and small: Organizational size, boundaries of the firm, and a changing environment. Academy of Management Annals, 9(1), 715-802.

Jung, H., Park, M., Hong, K., \& Hyun, E. (2016). The impact of an epidemic outbreak on consumer expenditures: An empirical assessment for MERS Korea. Sustainability, 8(5), 454.

Kaplan, R. S., \& Norton, D. P. (1992). The balanced scorecard: Measures that drive performance. Harvard Business Review.

Kaplan, R., \& Norton, D. (1996). Linking the balanced scorecard to strategy. California Management Review, 39(1), 53-79.

Kaptein, M. (2011). From inaction to external whistleblowing: The influence of the ethical culture of organizations on employee responses to observed wrongdoing. Journal of Business Ethics, 98(3), 513-530.

Kotter John, P., \& Heskett. (1992). Corporate culture \& performance. MacMillan.

Kutner, M., Nachtsheim, C., \& Neter, J. (2004). Applied linear regression models. McGraw-Hill/Irwin.

Li, S., Lin, Y., \& Selover, D. (2014). Chinese state-owned enterprises: Are they inefficient? The Chinese Economy, 47(5-6), 81-115.

Maunder, R., Hunter, J., Vincent, L., Bennett, J., Peladeau, N., Leszcz, M., ... \& Mazzulli, T. (2003). The immediate psychological and occupational impact of the 2003 SARS outbreak in a teaching hospital. Cmaj, 168(10), 1245-1251.

McManus, P. (2015). Introduction to regression models for panel data analysis. Indiana University Workshop in Methods.

Michalewicz, Z., \& Fogel, D. B. (2013). How to solve it: modern heuristics. Springer Science \& Business Media.

Minor, D., \& Morgan, J. (2011). CSR as reputation insurance: Primum non nocere. California Management Review, 53(3), 40-59.

Molenaar, K., Park, J., \& Washington, S. (2009). Framework for measuring corporate safety culture and its impact on construction safety performance. Journal of Construction Engineering and Management, 135(6), 488-496.

Mor, R., Jaiswal, S., Singh, S. \& Bhardwaj, A. (2019). Demand forecasting of the short-lifecycle dairy products. In: Understanding the role of business analytics (pp. 87-117). Springer.

Myers, S. (1984). The capital structure puzzle. The Journal of Finance, 39(3), 574-592.
Myers, R. (1995). Chinese debate on economic reform: Can China create a socialist market economy? Asian-Pacific Economic Literature, 9(2), 55-68.

Myers, S. (2001). Capital structure. Journal of Economic Perspectives, 15(2), 81-102.

Narayandas, D., Hebbar, V. \& Li, L. (2020). Lessons from Chinese companies' response to Covid-19. [online] Available at: https://hbr.org/ 2020/06/lessons-from-chinese-companies-response-to-covid-19. Accessed 12 July 2020.

Nicola, M., Alsafi, Z., Sohrabi, C., Kerwan, A., al-Jabir, A., Iosifidis, C., Agha, M., \& Agha, R. (2020). The socio-economic implications of the coronavirus and COVID-19 outbreak: A review. International Journal of Surgery, 78, 185-193.

Pinho, J., Rodrigues, A., \& Dibb, S. (2014). The role of corporate culture, market orientation and organisational commitment in organisational performance. Journal of Management Development, 33(4), 374 398.

PwC. (2020). COVID-19: What it means for forest, paper and packaging companies. [Online] Available at: https://www.pwc.com/us/en/ library/covid-19/coronavirus-impacts-forest-paper-packaging.html. Accessed 13 July 2020.

Raheman, A., \& Nasr, M. (2007). Working capital management and profitability-case of Pakistani firms. International Review of Business Research Papers, 3(1), 279-300.

Rajakaruna, S., Liu, W., Ding, Y., \& Cao, G. (2017). Strategy and technology to prevent hospital-acquired infections: Lessons from SARS, Ebola, and MERS in Asia and West Africa. Military Medical Research, 4(1), 32.

Ralston, D., et al. (2006). Today's state-owned enterprises of China: Are they dying dinosaurs or dynamic dynamos? Strategic Management Journal, 27(9), 825-843.

Ritter, T., \& Pedersen, C. (2020). Analysing the impact of the coronavirus crisis on business models. Industrial Marketing Management, 88, 214-224.

Schein, E. H. (1985). Defining organizational culture. Classics of organization theory, 3(1), 490-502.

Schleicher, A. (2020). The impact of COVID-19 on education insights from education at a glance 2020. Retrieved from oecd. org website: https://www.oecd.org/education/the-impact-of-covid-19-oneducation-insights-education-at-a-glance-2020.pdf.

Schröder, M. (2014). Financial effects of corporate social responsibility: A literature review. Journal of Sustainable Finance \& Investment, 4(4), 337-350.

Secinaro, S., Calandra, D., \& Biancone, P. (2020). Reflection on coronavirus accounting impact on small and medium sized enterprises (SMEs) in Europe. International Journal of Business and Management, 15(7), 48.

Serra, F., \& Ferreira, M. (2010). Emerging determinants of firm performance. Management Research: Journal of the Iberoamerican Academy of Management, 8(1), 7-24.

Sharma, A., \& Kumar, S. (2011). Effect of working capital management on firm profitability: Empirical evidence from India. Global Business Review, 12(1), 159-173.

Singh, M., \& Davidson III, W. (2003). Agency costs, ownership structure and corporate governance mechanisms. Journal of Banking \& Finance, 27(5), 793-816.

Stigler, G. (1958). The economies of scale. The Journal of Law and Economics, 1, 54-71.

Sun, Y., Bao, Q., \& Lu, Z. (2021). Coronavirus (Covid-19) outbreak, investor sentiment, and medical portfolio: Evidence from China, Hong Kong, Korea, Japan, and U.S. Pacific-Basin Finance Journal, 65, 101463. https://doi.org/10.1016/j.pacfin.2020.101463

Taylor, D. B. (2020). A timeline of the coronavirus outbreak. [online] Available at: https://www.nytimes.com/article/coronavirustimeline.html. Accessed 12 July 2020. 
Vigolo, V., Bonfanti, A., Magliocca, P., \& Kirakosyan, K. (2016). Corporate culture and firm performance: A service-oriented perspective. International Journal of Managerial and Financial Accounting, 8(2), 109-123.

Wahlen, J., Baginski, S., \& Bradshaw, M. (2014). Financial reporting, financial statement analysis and valuation. Nelson Education.

White, G. I., Sondhi, A. C., \& Fried, D. (2003). The analysis and use of financial statements. John Wiley \& Sons.

Williams, E. \& Dobelman, J. (2017). Financial statement analysis. In: World Scientific Book Chapters, pp. 109-169.

Wooldridge, J. (2015). Introductory econometrics: A modern approach. Nelson Education.

Zhang, D., Hu, M., \& Ji, Q. (2020). Financial markets under the global outbreak of COVID-19. Finance Research Letters, 36, 101528.
Zhao, H., Teng, H., \& Wu, Q. (2018). The effect of corporate culture on firm performance: Evidence from China. China Journal of Accounting Research, 11(1), 1-19.

Zikmund, W., Babin, B., Carr, J., \& Griffin, M. (2013). Business research methods. Nelson Education.

Zouaoui, M., Nouyrigat, G., \& Beer, F. (2011). How does investor sentiment affect stock market crises? Evidence from panel data. Financial Review, 46(4), 723-747.

Publisher's Note Springer Nature remains neutral with regard to jurisdictional claims in published maps and institutional affiliations. 